\title{
Candidate Genes and Political Behavior
}

\section{EVAN CHARNEY Duke University WILLIAM ENGLISH Harvard University}

\begin{abstract}
10 olitical scientists are making increasing use of the methodologies of behavior genetics in an attempt to uncover whether or not political behavior is heritable, as well as the specific genotypes that might act as predisposing factors for-or predictors of-political "phenotypes." Noteworthy among the latter are a series of candidate gene association studies in which researchers claim to have discovered one or two common genetic variants that predict such behaviors as voting and political orientation. We critically examine the candidate gene association study methodology by considering, as a representative example, the recent study by Fowler and Dawes according to which "two genes predict voter turnout." In addition to demonstrating, on the basis of the data set employed by Fowler and Dawes, that two genes do not predict voter turnout, we consider a number of difficulties, both methodological and genetic, that beset the use of gene association studies, both candidate and genome-wide, in the social and behavioral sciences.
\end{abstract}

$\mathbf{P}$ ractitioners of a growing subfield within political science-"genopolitics"-are committed to the proposition that the study of genetics can significantly enrich our understanding of the causes of political behavior. Over the past several years, they have conducted a number of studies aimed at measuring the extent to which differences in political behaviors are due to genes (as opposed to environment) and even at identifying the particular gene variants that contribute to these differences. This research has been premised on methodologies and assumptions that comprise a hybrid discipline known as behavior genetics. Long the purview of psychologists, behavior genetics searches for the genetic bases of human behavioreverything from mental illness to moral outlook. Inasmuch as the discipline is characterized by the assumption that any behavior that falls under the rubric of human behavior potentially has a "genetic component" (Turkheimer 2000)-no matter how culturally contingent it might appear-the migration of behavior genetics to political science can be seen as a natural development.

A watershed moment in this migration was the publication of a study by Alford, Funk, and Hibbing (2005) in which the authors claimed to have demonstrated that, when it comes to political ideology (specifically, whether one is a liberal or a conservative), genes count for more than environment. This claim was made on the basis of a methodology known as the workhorse of behavior genetics: the classical twin study. Twin studies are designed to measure heritability-the extent

Evan Charney is Associate Professor of the Practice of Public Policy and Political Science, Sanford School of Public Policy, Duke University, 250 Rubenstein Hall, 302 Towerview Drive, Duke Box 90311, Durham, NC 27708 (echar@duke.edu).

William English is Lab Fellow, Edmond J. Safra Center for Ethics, Harvard University, 124 Mount Auburn Street, Cambridge, MA 02138 (wenglish@ethics.harvard.edu).

Both authors contributed equally to this article. Research was supported in part by funding from the National Institutes of Health (Grant number: P50 HG003391) to which variation in a given trait (in a given population at a given time) is due to genetic, as opposed to environmental, differences. ${ }^{1}$ The study of Alford, Funk, and Hibbing was followed by studies purporting to demonstrate the heritability of the following: vote choice (Hatemi et al. 2007); attitudes toward abortion and gay rights (Eaves and Hatemi 2008); political participation, that is, voting behavior (Fowler, Baker, and Dawes 2008); cooperative behavior in the trust game (Cesarini et al. 2008); strength of party identification (Hatemi et al. 2009); and feelings toward the major federal parties, party identification, and vote choice (Bell, Schermer, and Vernon 2009).

A variant of the twin study was the original biometrical "natural experiment" proposed by Galton in 1876 (Plomin 1990), and the results of the first known classical twin study, based on the observed differences between identical and nonidentical twins, were published in 1924. A lot has changed in our understanding of genetics since then, and recent advances in molecular genetics are necessitating a rethinking of every one of the assumptions of the classical twin study methodology (Boklage 2009; Bruder 2008; Fraga et al. 2005; Haque, Gottesman, and Wong 2009; Marchetto, Gage, and Muotri 2010; Martin 2009; Notini, Craig, and White 2008; Ollikainen et al. 2010; Skipper 2008). However, the twin study methodology, which has been extensively critiqued elsewhere, is not our concern here. Rather, our concern is with the "second wave" of the turn to genetics in political science, involving the use of candidate gene association (CGA) studies, another methodology commonly used in behavior genetics.

The use of CGA studies in the social sciences has been facilitated both by the increasing availability of

\footnotetext{
1 Twin studies compare the extent to which identical twins (who are assumed to be genetically identical) exhibit concordance for a trait of interest (e.g., voting behavior) relative to fraternal twins (who are assumed to be $\sim 50 \%$ genetically identical). If identical twins show greater concordance for a trait, its cause is deemed to be genetic and an indication of heritability.
} 
large data sets that contain both behavioral data (usually in the form of self-reporting) and limited genetic data and by advances in statistical software and modeling techniques. In a typical CGA study, a researcher proposes that a gene variant, information for which is contained in the data set (e.g., whether or not a participant has a common variant of the MAOA gene), will predict a given behavior (e.g., voting behavior, as ascertained by responses to the question, "Did you vote in the last presidential election?"). If those who respond "yes" are more likely to possess this particular gene variant than those who respond "no," the gene is said to predict the behavior in question and, presumably, play a causal role in its variation (and development). The use of CGA studies by political scientists-as well as psychologists, sociologists, and economists-has yielded spectacular results. A particular gene (or gene variant) has been claimed to predict voting behavior (Fowler and Dawes 2008), "punishing behavior" in an experimental setting (McDermott et al. 2009), partisanship and party identification (Dawes and Fowler 2009), liberal political ideology (Settle et al. 2010), credit card debt (De Neve and Fowler 2010), antisocial personality (DeLisi et al. 2009), leadership (De Neve and Fowler 2010), and preferences for the voluntary provision of social goods (Mertins et al. 2011).

The number of recent claims by social scientists to have discovered a statistically significant association between a particular common gene variant-either on its own or in conjunction with a particular environment-and complex, politically relevant behaviors warrants careful evaluation. This evaluation is particularly needed because the search for genes that could predict prevalent and devastating behavioral phenotypes such as schizophrenia and autism, not to mention global killers such as diabetes and hypertension, has to date been unsuccessful (Dick, Riley, and Kendler 2010; Franke, Neale, and Faraone 2009; Plomin and Davis 2009; Talmud et al. 2010). The purpose of this article is to undertake such an evaluation.

After a short primer on basic genetic terms, we consider the 2008 CGA study of Fowler and Dawes in which the authors claim to have demonstrated that "two genes predict voter turnout," and identify difficulties that, given their prevalence, should be of concern to all who employ the CGA study methodology. These are the problems of phenotype specification, population stratification, genotype classification, and the independence of cases and controls. As we examine the findings of Fowler and Dawes through the lens of these problem areas, we argue that their claim cannot be sustained. However, we do not claim that the study of Fowler and Dawes is any more or less problematic than most other CGA studies in the social and behavioral sciences, and it is precisely for this reason that we use it as an example.

We then turn to the problem of the nonreplication of CGA studies in the social and behavioral sciences (and in genetics in general) and consider the likely reasons for this failure, the most obvious being that CGA studies of complex behavioral traits (such as political behaviors) rely on an outdated genetic paradigm.
Advances in molecular genetics over the past 25 years are bringing about what a number of researchers in the field have referred to as a "paradigm shift" (Sgaramella and Astolfi 2010). Any political scientist conducting a CGA study is engaged in research in both political science and genetics and so must be aware of cuttingedge research in both disciplines. This is particularly the case when, as we see, cutting-edge research in genetics has direct bearing on the validity of the methodologies used. Finally, we highlight statistical difficulties attendant both on the proliferation of associations between the same genotypes and an ever-expanding array of phenotypes and on the widespread utilization of the same data sets.

\section{PRELIMINARIES}

\section{Alleles}

Genes are segments of DNA coded for the production of specific proteins. Each person possesses two copies of each gene in all the cells of his or her body (except for sperm and egg cells, red blood cells, and genes located on the $\mathrm{X}$ and $\mathrm{Y}$ chromosomes in males), one copy of which comes from the mother and one from the father. ${ }^{2}$ Each of the copies of a gene is called an allele of the gene. Alleles of a gene from the two parents may be identical, or they may differ slightly; sometimes they differ by only a single nucleotide substitution (nucleotides are the basic subunits that make up the DNA molecule). These minor structural differences between alleles can be found in many different configurations or "versions." When two or more versions of an allele for a single gene occur in $>1 \%$ of a given population, it is referred to as a polymorphism. A version of an allele that occurs in $<1 \%$ of the population is called a mutation. The term "genotype" can be used to refer to an individual's entire DNA sequence (in which case it is usually called one's "genome") or any number of his or her genes, or a single polymorphism, or a mutation. Hence, it is common to refer to an individual's genotype when referring to whether he or she possesses a particular allele.

When both of the alleles for a given gene are identical, then one is homozygous for that gene; when the alleles differ, one is heterozygous. Suppose that gene A comes in two common forms (polymorphisms): allele $A_{1}$ and allele $A_{2}$. A claim for an association in a CGA study generally takes the following form: Those with

\footnotetext{
2 This characterization refers only to nuclear DNA, the DNA molecule contained in the nucleus of most cells in the body. This is not true of the other, distinct genome that persons possess-mitochondrial DNA (mtDNA). mtDNA is located within small structures (organelles) in cells known as mitochondria that are involved in the production of cellular energy. mtDNA is inherited solely from the mother and exhibits what is known as polyploidy: numerous copies of the entire mtDNA molecule per cell, the number of which varies by cell type anywhere from 1,200-10,800 copies per cell in neurons to $11,000-903,000$ copies per cell in female egg cells (Clay Montier, Deng, and Bay 2009). Because mtDNA is stochastically partitioned when a fertilized egg cell divides, so-called identical(monozygotic) twins do not have identical mitochondrial genomes.
} 
allele $\mathrm{A}_{1}$ are more likely to display behavior $\mathrm{X}$ than those with allele $\mathrm{A}_{2}$ (or vice versa), or those homozygous for gene $\mathrm{A}$ (alleles $\mathrm{A}_{1} \mathrm{~A}_{1}$ or $\mathrm{A}_{2} \mathrm{~A}_{2}$ ) are more likely to display behavior $\mathrm{X}$ than those who are heterozygous (alleles $\mathrm{A}_{1} \mathrm{~A}_{2}{ }^{3}$ ), or vice versa.

\section{Study of Fowler and Dawes}

In 2008, James Fowler and Christopher Dawes (FD) published an article in the Journal of Politics titled "Two Genes Predict Voter Turnout," in which they reported the discovery of both a gene and a gene-byenvironment $(G \times E)$ interaction that increased the likelihood of voting. Persons having the "high" variant of the gene MAOA, which encodes the enzyme monoamine oxidase, voted at a higher rate than those with the "low" variant (an odds ratio of $1.26, p=.03$ ); persons having a "long" variant of the gene 5-HTT, which encodes the serotonin transport protein, and who also attended religious services voted at a higher rate than those who did not share this $G \times E$ interaction (odds ratio of $1.58, p=.006$ ). Naturally the claim that two common gene variants could predict voter turnout received a good deal of attention in both the discipline and the press and was praised as "the first results ever to link specific genes to political behavior" (Science Daily 2008).

To conduct their study, FD made use of the $\mathrm{Na}$ tional Longitudinal Study of Adolescent Health (Add Health) data set, derived from a study designed to explore a variety of behavioral and health attributes of adolescents in grades 7 through 12. Data from three waves are currently available (and a fourth has just been released). In Wave I (1994-95), students and parents were administered in-home surveys (a core random sample of 12,105 adolescents in grades 7-12 plus several oversamples, totaling more than 27,000 adolescents). In Wave II (1996), another set of inhome interviews of more than 15,000 students from the Wave I sample was conducted. Finally, Wave III (200102) consisted of an in-home interview six years later of 15,170 Wave I participants. In Wave I, researchers identified a "genetically informative sample of sibling pairs," which included "all adolescents that were identified as twin pairs, half siblings, or unrelated siblings raised together." In Wave III, genetic information consisting of zygosity (i.e., twin) status and genetic data for eight genes were solicited from twins and full siblings in this subsample $(3,787$ were asked to provide genetic material, of whom $2,574 \mathrm{did}) .^{4}$

In their analysis, FD employed a mixed effects logit model (as proposed by Xu and Shete [2007]) to investigate the relationship among candidate genes, environmental factors, and voting. Their model controls for various mediating factors that might influence voting

\footnotetext{
${ }^{3}$ In discussing the alleles of a gene, order does not matter (i.e., $\mathrm{A}_{1} \mathrm{~A}_{2}$ is equivalent to $A_{2} A_{1}$ ).

4 "Biomarkers in Wave III of the Add Health Study," Add Health Biomarker Team, p. 6. http://www.cpc.unc.edu/projects/addhealth/ data/guides/biomark.pdf (accessed November 10, 2011).
}

(such as age and ethnicity) and clusters random effects through a family ID (a unique identifier given to each household). The utility of using a logistic model to investigate the correlates of a binary independent variable (voting) is straightforward, as is the incorporation of standard control variables. The mixed effects model additionally incorporates "random effects" to account for the presumed correlation among family members. The model FD employed to investigate the hypothesized link between MAO-A and voting (Model 1) involved no interaction terms, whereas the model for 5-HTT (Model 4) involved an interaction between the "environment" (religious attendance) and the 5-HTT allele. The details and results of FD's two main models are contained in our table of final results (Table 1, cols. $\mathrm{A}$ and $\mathrm{B})$.

\section{FOUR PROBLEM AREAS}

\section{Phenotype Specification}

A phenotype is the observable expression of an individual's genotype (Wojczynski and Tiwari 2008). CGA studies are based on a case-control design in which gene frequency in "cases"-study subjects who exhibit the phenotype being investigated-is compared with frequency in "controls," subjects who do not exhibit the phenotype. Careful selection of cases and controls is necessary to avoid potential confounding effects: Cases must meet appropriate criteria for possessing the phenotype under consideration, and controls must not exhibit the phenotype and must be free from potential associated intermediate phenotypes (Chanock et al. 2007). Any ambiguity in phenotypic specification will have the likely effect of confounding cases and controls, leading to spurious associations (Bickeböller et al. 2005). The problem of ambiguity is particularly acute in relation to complex behaviors such as voting. Because FD distinguish their cases-"voters"-from controls, "nonvoters," on the basis of their "voting behavior," but do not define these terms, we must infer the intended phenotype.

In the final sections of the Wave III questionnaire, participants were asked a series of questions concerning "Civic Participation and Citizenship" and "Religion and Spirituality." Included in the former section was the question, "Did you vote in the most recent presidential election?" FD classified those who responded "yes" as "voters" and those who responded "no" as "nonvoters." Included in the section of religion and spirituality was the question, "How often have you attended [various kinds of] religious services in the past 12 months?"; responses to this question were the basis for determination of the church-attendance phenotype.

It is apparent that responses to the question, "Did you vote in the most recent presidential election?," do not provide information concerning what is usually intended by the expression "voting behavior." For example, they do not provide any information concerning voting frequency; that is, whether, according 


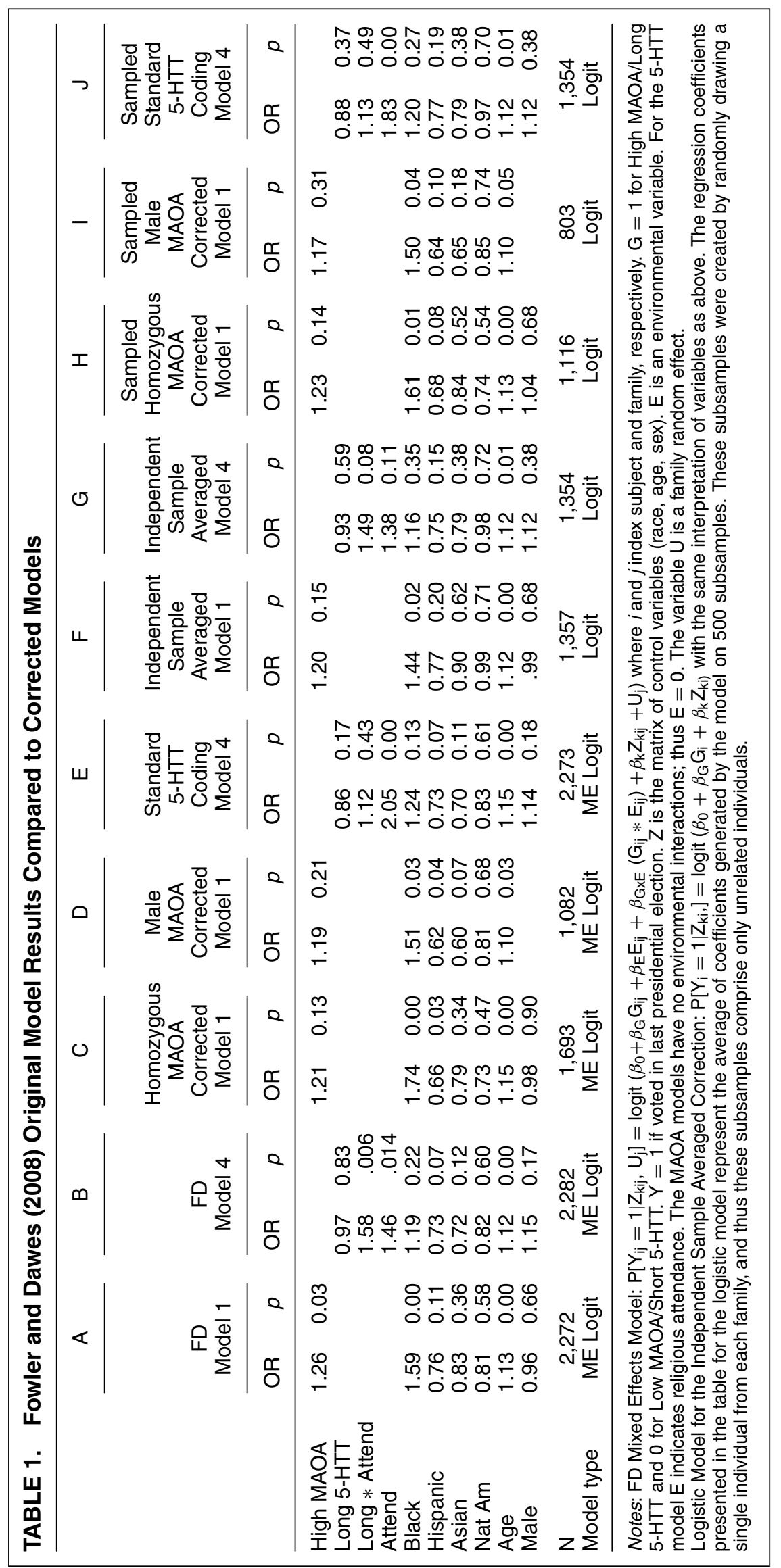


to a common classification, respondents are habitual, intermittent, or rare voters (Plutzer 2002). What the data do tell us is whether a subject voted at least once in a presidential election. FD $(2008,584)$ are aware of this difficulty and speculate that perhaps the association between two genes and voting behavior applies "only to the initiation of turnout behavior in adults, and not to its subsequent development as people age." Because FD provide no further specification of this new phenotype - "the initiation of voting behavior"we must again infer the intended designation. The most reasonable interpretation of this expression in this context is the age (or age range) when an individual votes for the first time (beginning with age 18, the legal age of voting in the United States).

The Add Health Wave III questionnaire was administered in 2001-02 to subjects who at that time were between the ages of 18-26, and all of their responses concerned the 2000 presidential election. FD restricted their analysis to those who were 18 or older in November 2000 (and thus eligible to vote), which yields a voting population of those who were 18- to 24-yearsold in 2000. We cannot assume, however, that an older respondent who did not vote in the 2000 presidential election also did not vote in the 1996 presidential election (the earliest presidential election for which any of the respondents would have been eligible to vote). Moreover, all respondents older than age 20 in November 2000 would have been eligible to vote for the first time in the mid-term elections of 1998. If we use FD's model to look only at those who faced their first opportunity to vote in November 2000 (those aged 18$20, n=514)$, the MAOA relationship actually trends in the opposite direction ( or $=.90, p=.61$ ). By contrast, the age 20-22 cohort (those who, if we count midterm elections, were facing their second opportunity to vote) displays a positive and statistically significant result: or $=1.42, p=.019(\mathrm{n}=873)$. For a third cohort comprised of those 22 and older, the relationship trends downward and is no longer significant: or $=1.21, p=$ $.216(\mathrm{n}=876)$. Similarly, in relation to long 5-HTT, we see a statistically significant result only in the $20-22$ age cohort.

It is not entirely clear how to interpret these results, and at methodological level, whether and how to pool the "genetic effects" across voting cohorts are open to debate. We wish only to raise these issues surrounding the heterogeneity of genetic effects at the outset, and we return to questions relating to voter cohort in the context of other methodological problems with this study. Breaking down the study population into distinct voting cohorts by age, however, was motivated by an attempt to give as much precision as possible to an underspecified phenotype.

The problem of phenotypic specification we have identified is by no means unique to the study of FD. Many factors can contribute to the inadequate specification of a phenotype, but two common causes are what might be termed "inherent imprecision" and treating quantitative variables as if they are dichotomous variables. Inherent imprecision is a natural feature of human language. A "vote" is defined as a formal expres- sion of opinion or choice. This definition encompasses voting among friends to choose a movie to see, voting in a faculty meeting to hire a job candidate, or voting in a parliamentary election. Even acts of voting that are qualified (e.g., "voting in a national political election") may have more or less in common: Voting in a country where voting in national political elections is mandatory (i.e., enforced by law, as in Australia) is in important ways a different behavior than voluntary voting in the United States, as is voting in a country where one risks one's life by showing up at the voting booth or voting for the wrong candidate, or where the results of the election are predetermined.

The tendency to treat quantitative variables as dichotomous can result from limitations in the data as well as limitations in the methodology. The Add Health data set, for example, contains only dichotomous voting data-the respondent either did or did not vote in the previous presidential election. As commonly intended, however, the expression "voting behavior" refers to a quantitative variable (i.e., one votes more or less frequently). In CGA studies, this tendency is also fostered by the common practice of dichotomously partitioning the presumed behavior of genes (e.g., the MAOA gene comes in a high and low variant, the 5HTT gene comes in a long and short variant). Because the objective is to associate these dichotomous alleles with differences in behavior, the tendency (or temptation) is to conceptualize the behavior in question in a dichotomous manner as well-particularly if other means of quantification are not readily available or if a dichotomous rendering proves easier for establishing statistical significance.

Finally, with regard to phenotype measurement, the use of Add Health voting data is complicated by the well-documented problem of over-reporting (Ansolabehere and Hersh 2008; Cassel 2003; 2004), something that FD recognize but dismiss. Within Wave III of the Add Health data, however, we did see nine subjects who report both that they are not registered to vote and that they voted (these questions were administered sequentially). We excluded these nine from our analysis because of the inconsistency of their responses, although the effects are generally negligible (because of the anonymous nature of the data it is impossible to verify responses using voter registration records).

\section{Population Stratification}

Population stratification refers to the fact that allele frequencies are known to differ in different populations and subpopulations (Cavalli-Sforza 1994). Ethnic populations can exhibit allele-frequency difference as a result of unique ancestral patterns of migration, mating practices, and reproductive expansions and bottlenecks (Hunley, Healy, and Long 2009). These populationfrequency discrepancies are widespread throughout the genome, including many genes of known physiological relevance (Stephens et al. 2001). Nearly all outbred (i.e., nonfamilial) populations are confounded by genetic admixture at some level. The challenge is 
not merely to show that population stratification exists, but to avoid making erroneous conclusions because of it (Cardon and Palmer 2003).

The alleles of MAOA and 5-HTT are no exception in exhibiting population stratification (Balciuniene et al. 2001; Esau, Adonis, and Arieff 2008). For example, as FD note, the percentage of whites in the U.S. population carrying the high MAOA allele $(53.4 \%)$ is much larger than the percentage of Asian Americans $(31.9 \%)$. At the same time, studies have shown that whites in the United States vote at a much higher rate than Asian Americans (File and Crissey 2010). This raises the possibility that the association between high MAOA and voting is an artifact of cultural differentiation. By using dummy variables for ethnicity in their mixed effects logit model, FD allow for different racial/ethnic groups having different baseline voting rates independent of the genetic effects under consideration. In so doing, they assume that it is appropriate to pool the genetic effects across different ethnic groups (i.e., that the effects that a gene has on voter turnout are similar or constant across each of the subpopulations).

However, when broken down by ethnicity, the presumed genetic effects turn out to be surprisingly heterogeneous. The Add Health questionnaire, like many demographic surveys conducted in the United States, asks about Hispanic identification separately, so nearly all self-identified Hispanics also identify with another racial category, with the majority self-identifying as white. On investigation, we discover that in the case of Asians, Native Americans, and nonwhite Hispanics, the link between high MAOA and voting is not only not significant but also trends in the opposite direction: Asian (or $=.79, p=.59, n=141$ ), Native American (or $=$ $.39, p=.16, n=52$ ), and nonwhite Hispanic (or $=.51$, $p=.25, n=68$ ). Whites (without Hispanics) show a result closer to FD's main findings with an odds ratio of 1.25, but bordering on the edge of statistical significance with a $p$-value of $.093(n=1,434)$. Moreover, with Hispanic whites we find a higher odds ratio of 1.36 , but the result is not significant, with a $p$-value of $.43(n=$ 207). Finally, the population of self-identified African Americans exhibits an odds ratio of 1.61, well above FD's finding, and a $p$-value just under the threshold of significance at $.049(n=429)$. Hence, the presumed effects of MAOA on voting are not stable across different ethnic subgroups, and the results of FD's analysis are heavily influenced by the uniquely strong association with African American voters. If we drop African Americans from the data set, the result for all other racial groups combined yields an odds ratio of 1.18 and a $p$-value of $.16(n=1,834)$.

What could account for this finding? As we demonstrate later, there may be nothing to account for once other problems are corrected. Nonetheless, let us assume that this significant association with the African American population is genuine. For the most part, alleles assort independently. Parents, like their offspring, possess two alleles for every gene, and during the formation of gametes (egg and sperm) this number is halved. Suppose that one parent is heterozygous for two genes, A and B (i.e., he or she has the genotypes
$\mathrm{A}_{1} \mathrm{~A}_{2}$ and $\left.\mathrm{B}_{1} \mathrm{~B}_{2}\right)$. Independent assortment means that any given egg or sperm cell might contain any of the following combinations of alleles: $\mathrm{A}_{1} \mathrm{~B}_{1}, \mathrm{~A}_{1} \mathrm{~B}_{2}, \mathrm{~A}_{2} \mathrm{~B}_{1}$, or $A_{2} B_{2}$. Yet this is not always the case. For various reasons, including if the genes $\mathrm{A}$ and $\mathrm{B}$ are located close to each other on the same chromosome, certain alleles from each gene may tend to be inherited together more often than not (e.g., $\mathrm{A}_{1}$ tends to be inherited together with $B_{2}$ ). In a situation such as this, the alleles $A_{1}$ and $\mathrm{B}_{2}$ are said to be in "linkage disequilibrium." $\mathrm{A}$ haplotype is the name given to combinations of three or more common alleles (i.e., polymorphisms) in linkage disequilibrium with each other (i.e., they all tend to be inherited together; Morton 2005).

Geneticists have established that the haplotypes of MAOA and 5-HTT are significantly different in European American than in African American populations (Balciuniene et al. 2001; Lotrich, Pollock, and Ferrell 2003). Assuming, for the sake of argument, that the association between a polymorphism of MAOA and voting is statistically significant, one might propose the following: A polymorphism of MAOA does not predict voter turnout; rather, a gene that is in linkage disequilibrium with a polymorphism of MAOA and occurs at a higher rate among African Americans predicts voter turnout. What this would show is that it is inappropriate to pool the presumed genetic effects of MAOA across European and African American populations. With regard to 5-HTT, the situation is similarly complex although less dramatic. When broken down by ethnic identification, the effects trend in the same direction, although they vary greatly in magnitude and significance: African Americans: or $=2.75, p=.08(n=$ 428); Asians: or $=2.12, p=.17(n=142)$; non-Hispanic whites: or $=1.22, p=.37(n=1441)$; Hispanic whites: or $=2.03, p=.22(n=210)$; Native Americans or $=$ $4.33, p=.21(n=52)$; and Hispanic nonwhites: or $=$ $5.83, p=.14(n=68)$.

\section{Genotype Classification}

One of the principal findings of FD is that a polymorphism of the MAOA gene is associated with voting behavior. Monoamine oxidase A (MAO-A) is an enzyme that helps break down a class of neurotransmitters known as monoamines-including adrenaline, noradrenaline, dopamine, and serotonin-thereby diminishing their bioavailability. The gene that is coded for MAO-A is characterized by polymorphisms in its promoter region, a segment of DNA located upstreamfrom a gene's coding region near the site where gene transcription is initiated. This polymorphism is characterized by tandem repeats, the replication of two or more nucleotide sequences directly adjacent to each other. For example, a triple or 3-tandem repeat of the 5 base pair (bp) nucleic acid sequence A-T-TC-G, would have the form, A-T-T-C-G-A-T-T-C-GA-T-T-C-G. The repeating sequence in MAOA is 30 bp in length, and polymorphisms with $2,3,3.5,4,5$, and 6-tandem repeats have been identified (Zhu and Shih 1997). Because the number of tandem repeats is 
variable, the polymorphism is designated a variable number tandem repeat ( $\mu \mathrm{VNTR})$.

Transcription is the process in which the DNA molecule is used (by a cell) as a template to produce messenger RNA (mRNA), which in turn serves as a template for protein synthesis (translation). On the basis of experiments with cells in the laboratory (in vitro analysis), there is a widespread assumption that the different tandem repeats of MAOA- $\mu$ VNTR exhibit different levels of transcriptional efficiency (i.e., different transcription rates). A difference in transcription rates is presumed to translate into different levels of bioavailable MAO-A in the brain, which in turn is presumed to translate into different levels of bioavailable serotonin (5-HT), yielding the following causal schematic: High/low MAOA- $\mu$ VNTR $\rightarrow$ high/low levels of brain MAO-A $\rightarrow$ high/low levels of brain 5-HT. Finally, the different levels of serotonin in the brain are presumed to translate into differences in phenotypes (such as voting behavior).

In fact, it is by no means clear that high and low alleles of MAOA- $\mu$ VNTR correspond to higher and lower levels of brain serotonin. Studies that have attempted to demonstrate the effects of MAOA-uVNTR genotypes on in vivo (as opposed to in vitro) brain levels of MAO-A have had mixed, largely negative results (Alia-Klein et al. 2008; Cirulli and Goldstein 2007; Fowler et al. 2007; Nordquist and Oreland 2010). According to a recent review (Nordquist and Oreland 2010, 2), "in adult humans, and monkeys with orthologous genetic polymorphisms [polymorphisms having the same function in two different species], there is no observable correlation between these functional genetic variants [of MAOA] and the amount or activity of the corresponding proteins in the brain."

Nonetheless, on the basis of in vitro analysis, the 3.5 and 4 MAOA- $\mu$ VNTR repeat alleles have been classified as being transcribed 2 to 10 times more efficiently than alleles containing the 3 -tandem repeat (Sabol, $\mathrm{Hu}$, and Hamer 1998). Hence, the 3 repeat allele is classified as "low" ( $l$ MAOA- $\mu$ VNTR $)$, for low transcriptional efficiency, and the 3.5 and 4 repeat alleles as "high" ( $H$ MAOA- $\mu$ VNTR), for "high transcriptional efficiency. There is no consensus, however, regarding the transcriptional efficiency and, hence, the appropriate classification of the less commonly occurring 2, 5, and 6 repeat alleles. For example, according to Sabol, Hu, and Hamer (1998), the 5 repeat allele exhibits low transcriptional efficiency, whereas according to Deckert et al. (1999), it exhibits high transcriptional efficiency. According to Pai, Chou, and Huang (2007) the 2 repeat allele exhibits higher transcriptional efficiency (and should be ranked with the 5, 3.5, and 4 alleles), but according to Young et al. (2006) it should be classified as low. FD follow Deckert et al. (1999) and classify the 2 repeat allele as low and the 5 repeat allele as high. They do not, however, provide any specific justification for this decision (and in this they follow most other researchers in the social and behavioral sciences). Different classificatory systems have given rise to the unusual situation in which researchers com- monly classify the 2 and 5 repeat alleles ad libitum in the absence of any specific justification for doing so.

In females, the classification of MAOA- $\mu$ VNTR alleles as high or low is extremely problematic. This is because males possess only a single $\mathrm{X}$ and a single $\mathrm{Y}$ chromosome (i.e., they are XY), whereas females possess two $\mathrm{X}$ chromosomes but no Y chromosome (they are $\mathrm{XX}$ ). Because the MAOA gene is an X-linked gene (i.e., is located on the $\mathrm{X}$ chromosome), males possess only a single MAOA allele, a condition referred to as hemizygosity, in contrast to females who, being $\mathrm{XX}$, possess two MAOA alleles. Hence, the classificatory schemes that we have been discussing (e.g., the 3.5 repeat allele is high, and the 3 repeat allele is low) apply only to males, who are hemizygous for the MAOA gene (Wachtel 1994).

In females, the situation is different and extremely complicated. To achieve what is termed "dosage compensation," most of the "secondary" alleles on either of the female X chromosomes are "silenced" (i.e., rendered incapable of being transcribed, through an epigenetic ${ }^{5}$ process known as $\mathrm{X}$ chromosome inactivation; Migeon 2007). However, about $15 \%$ of these secondary alleles escape inactivation entirely, and an additional $10 \%$ show varying degrees of inactivation (Carrel and Willard 2005). These variable patterns of inactivation entail significant heterogeneity in X chromosome inactivation between any two females, and they also result in higher levels of gene expression in at least $15 \%$ of X-linked genes in females than in males, inasmuch as they exhibit bi-allelic expression. To further complicate matters, different cells and tissues need not exhibit the same pattern of X chromosome inactivation: One and the same allele in one and the same individual might be completely inactivated in one set of tissues (e.g., the brain), partially inactivated in another, and completely active in a third (Migeon 2007).

There exists no scientifically sound way to classify the bi-allelic expression of MAOA genes in females as either "high" or "low," and it is for this reason that females are often excluded from MAOA candidate gene association studies (Kim-Cohen et al. 2006). For example, if a female is homozygous for two alleles and is $l-l$ or $H-H$, we have no way of knowing if only one of these alleles is active, if both are completely active, if both are partially active, or if one is active and the other partially active. Nor do we know to what extent a given pattern of inactivation persists throughout all the cells and tissues of the body. If a female is heterozygous $(l-H)$, it should (presumably) make a significant difference whether the gene that escapes inactivation is $l$ or $H$. Furthermore, if females are to be combined with males in the study population, can we assume, for example, that $l-l$ females should be classified as "low" when both alleles might be active? Does a bi-allelically expressed $l-l$ female exhibit transcriptional efficiency

\footnotetext{
5 An epigenetic process refers to the "epigenome," the complex regulatory system that turns individual genes on and off (i.e., controls the extent to which they are capable of being transcribed).
} 
equivalent to a mono-allelic $l$ MAOA- $\mu$ VNTR male or a mono-allelic $H$ MAOA- $\mu$ VNTR male? And what of bi-allelic expression in females in which one of the alleles is partially expressed?

These questions have not stopped some researchers interested in conducting CGA studies that include female subjects from proposing universal classificatory schemes for female MAOA genotypes. Frazzetto et al. (2007), for example, classify female MAOA genotypes as follows:

1. Homozygous subjects carrying two low-activity alleles $(l-l)$ are Low.

2. Homozygous subjects carrying two high-activity alleles $(H-H)$ are High.

3. Heterozygous subjects carrying one low- and one high-activity allele $(l-H)$ are Intermediate.

Others have followed Frazetto et al. in the classification of (1) and (2), but have classified (3) as low (Jacob et al. $2005)$. Fowler and Dawes $(2008,585$, note 8 ) claim to be following the classificatory schema of Frazzetto et al. (2007) when they assert, "For the MAOA gene, $G=1$ if the subject's genotype is $\mathrm{HH}$, and $\mathrm{G}=0$ for genotypes $\mathrm{Hl}$ or $\mathrm{ll}$ (where $\mathrm{H}$ represents having a copy of a 336, 351, or 381 base-pair 'high' allele, and 1 represents having a copy of a 291 or 321 base-pair 'low' allele)." Frazzetto et al., however, do not classify all heterozygous females as "low," but rather as members of an "intermediate" category.

One way to deal with the potential misclassification of $l-H$ females is to exclude them altogether and consider only homozygous females (i.e., both copies of their X chromosome contain the same base-pair alleles, which are then coded in the same manner as males). Using this classification scheme, which excludes all heterozygous females (resulting $n=1,693$ ), the association between MAOA and voting becomes weaker (or $=1.21)$ and is no longer statistically significant ( $p=.13$; Table 1, column C). However, given the problems of differential transcriptional efficiency, variable $\mathrm{X}$-chromosome inactivation, and bi-allelic expression, the only scientifically sound approach is to exclude females from the study population altogether (resulting $n=1,082$ ). Doing this yields an odds ratio of 1.19 and a $p$-value of .21, indicating that that there is no statistically significant relationship between MAOA and voter turnout (Table 1, column D).

We confront similar difficulties in relation to the polymorphisms of the serotonin transporter gene (5HTT), located in the transporter-linked polymorphic region (LPR; combining the two terms yields "5HTTLPR"). Two polymorphisms have been identified in this region that, as in the case of MAOA- $\mu$ VNTR, have been associated with differences in transcriptional efficiency as a result of in vitro analysis (Heils et al. 1996). These polymophisms are dichotomously classified as "long" (L), denoting higher transcriptional activity, and "short" (s), denoting lower transcriptional activity (Lesch et al. 1996). As was the case with MAOA, there is no consensus as to whether these in vitro differences actually translate into meaningful dif- ferences in vivo (Naylor et al. 1998; Shioe et al. 2003; Willeit et al. 2001).

FD $(2008,585)$ claim to be following Caspi et al. (2003) when they classify the L and s alleles as follows: "Previous research has shown that being homozygous for the short allele (ss) makes one more vulnerable to negative environmental stimuli compared to being heterozygous for the short allele or homozygous for the long allele (Ls or LL; Caspi et al. 2003). Therefore, we combined Ls and LL into the Long genotype and ss into the Short genotype." This is not, however, how Caspi et al. $(2003,386)$ classify these alleles: "Individuals with one or two copies of the short allele of the 5HTT promoter polymorphism exhibited more depressive symptoms, diagnosable depression, and suicidality in relation to stressful life events than individuals homozygous for the long allele." In other words, they classify the genotypes ss and Ls as short and the LL genotype as long. The vast majority of CGA studies involving 5-HTTLPR also use this classification, although there is at least one report suggesting a classification scheme parallel to that used by FD (Williams et al. 2003). When one codes the 5-HTT data as Caspi et al. and the majority of other researchers do, there is no longer a statistically significant association. Rather than a Long*Attend odds ratio of 1.58 and a $p$-value of .006 , the model yields an odds ratio of 1.12 and $p$-value of .42 , indicating there is no significant relationship between the hypothesized 5-HTT*Attend interaction and voting (Table 1, column E).

\section{Independence of Cases and Controls}

We turn now to a significant problem generated by the limitations of the particular data set used by FD and numerous other researchers. The genetic data in the Third Wave of the Add Health study is not a randomized sample of the population at large, but rather a "genetically informed sampling of sibling pairs" (i.e., genetic samples were sought only from subjects with siblings who were also participating in the study, siblings being defined as "all adolescents that were identified as twin pairs, half siblings, or unrelated siblings raised together"). Because of nonresponses, nearly 500 subjects (472 with 5-HTTLPR data and 481 with MAOA- $\mu$ VNTR data) are not matched with siblings. ${ }^{6}$ However, among the remaining $\sim 1,800$ subjects with complete sibling genetic data, approximately $57.8 \%$ are full siblings, $19.2 \%$ are dizygotic (fraternal) twins, $12.8 \%$ are monozygotic (identical) twins, $4.2 \%$ are unrelated "siblings" who live in the same household, $2.3 \%$ are half-siblings, $1.6 \%$ are cousins, and $2.1 \%$ are unclassified. Moreover, the sibling composition itself is unrepresentative: In the U.S. general population, approximately $1.6 \%$ of siblings are fraternal twins (compared with $19.2 \%$ in the Add Health data), and

\footnotetext{
${ }^{6}$ Because of both nonresponses on variables of interest (such as church attendance) and occasional problems with the biological sample itself, the total populations for MAOA- $\mu$ VNTR and 5-HTTLPR analysis differ slightly.
} 
approximately $0.8 \%$ are identical twins $(12.8 \%$ in the data). ${ }^{7}$

Although participants from the same household were given a common family identifier (ID), this ID does not indicate the nature of the sibling relationship (i.e., it does not designate whether siblings in the same household were full siblings, half-siblings, fraternal twins, identical twins, cousins, unrelated siblings, or "unclassified"). The sampling focus on siblings, the overrepresentation of twins, and the heterogeneity of relationships included under the common rubric of a family ID create a significant problem if (1) the trait under consideration is potentially influenced by family environment and/or (2) the hypothesized genetic influences are confounded by degrees of genetic similarity between family members. Clearly, there are good reasons to believe that voting is a behavior influenced by family environment (McIntosh, Hart, and Youniss 2007). Moreover, both the shared environment and genetic profiles of "siblings" vary systematically depending on whether they are identical twins, fraternal twins, siblings of different ages, cousins, or unrelated persons living in the same house.

Traditional case-control studies assume the independence of cases and controls. The fact that both cases and controls in the genetic subsample of the Add Health data set are predominantly siblings who grew up in the same environment violates this assumption. The problem here concerns the potential effects of genetic as well as environmental similarities: It is important to account for correlation among family members because identity by descent (IBD) sharing of alleles can inflate the probability of type I errors and lead to an increase in false positives (Newman et al. 2001). Moreover, in the presence of population substructures, case-control studies can produce spurious associations (Marchini et al. 2004). Therefore the challenge is to disambiguate "pure" environmental effects, $\mathrm{G} \times \mathrm{E}$ interaction effects, genetic effects of a candidate gene, and genetic effects correlated among close relatives but not linked to the candidate gene.

The most obvious way to address this challenge is to restrict analysis to unrelated individuals (who also do not reside in the same household). This can be done by randomly sampling a single individual from each family cluster. However, in a study such as Add Health, doing so would result in a decrease in sample size and statistical power. To deal with this decrease, FD adopt a method proposed by $\mathrm{Xu}$ and Shete (2007). Xu and Shete use a basic simulation to show that a mixed effects logit model, employing random effects to account

\footnotetext{
${ }^{7}$ Precise population-wide estimates of twin rates are difficult to obtain, both because the determination of zygosity is either noisy (Machin 2009) or expensive and because the rate of twin births has risen some $70 \%$ since 1980 due to the increased use of in vitro fertilization (Births: Final Data for 2006, http://digitalcommons.unl.edu/ publichealthresources/65). However, twin population estimates in the epidemiological and demographic literature are, in any case, an order of magnitude different from the percentages represented in the Add Health Data. See National Vital Statistics Reports, Volume 58, Number 24, August 9, 2010 (page 2; http://www.cdc.gov/nchs/ data/nvsr/nvsr58/nvsr58_24.pdf), and Pergament (2005, 625).
}

for the correlation between family members, can help control the possibility of type 1 errors in case-control studies of family members.

Following $\mathrm{Xu}$ and Shete, FD attempt to correct for family relatedness by clustering random effects through the family ID in their mixed effects logit model. However, the categorization of sibling relationships employed in the Add Health data set-identical twins, fraternal twins, siblings, half-siblings, etc.-makes the use of such an approach particularly problematic. The mixed effects logit model assumes that random effects of family clusters are independent and identically distributed, with a mean of zero and a constant variance (Neuhaus, Hauck, and Kalbfleisch 1992). However, the Add Health data clearly do not possess the normally distributed heterogeneity often assumed of generic family data. This is because the "families" in the Add Health data set segregate into different "types" whose members differ systematically both in terms of degree of genetic similarity (e.g., identical twins vs. unrelated siblings living in the same household) and environmental similarity (e.g., high number of twin pairs vs. nontwin siblings). It makes little sense to assume that a single clustered random effect is adequate to control for the diverse latent effects (genetic and environmental) that are unevenly yet systematically distributed across different family types. Simply put, FD's mixed effects model demands a distribution of "family effects" that the very design of the Add Health study likely precludes.

The use of the mixed effects model presents further difficulties. As Larsen et al. (2000, 913) note, the interpretation of fixed effects parameters in the presence of random effects is not always straightforward: "When introducing random effects in the linear predictor in a logistic regression model, the interpretation of the mixed effects usually changes for one or more of the fixed effects." And as Xu and Shete $(2007,231)$ explain of the mixed effects model, "By including only the random intercept $u i$, and keeping the effect of the risk locus fixed, we assume that there is a specific probability of being affected in each family but that the effect of risk locus is identical across the families." In addition to doubts about modeling family effects as independent and identically distributed, the structural assumption of uniform fixed effects across families is also open to question. Finally, as $\mathrm{Xu}$ and Shete note, other statisticians have proposed alternative methods for incorporating family data into case-control studies. Most of these alternative methods are particularly sensitive to heterogeneity in degrees of kinship. For example, Bourgain et al. (2004) and Browning et al. (2005) propose accounting for the correlation of family members by calculating kinship coefficients and appropriately weighting each individual. For the Add Health data, in which nearly half of the "families" are composed of respondent pairs who are not "traditional siblings," incorporating a measure of degree of kinship is likely to be particularly important.

In summary, the mixed effects logit model that FD employ in an attempt to correct for the various kinds of confounding bias that may accompany a case-control 
study with family data appears ill suited for dealing both with the problems presented by the Add Health family sampling and the particular behavior under investigation. Moreover, at first glance the data suggest that there are indeed latent family effects on voting. Approximately $65.2 \%$ of respondents in the same family "match" each other's voting behavior: Either both responded "yes" to the question, "Did you vote in the last presidential election?," or both responded "no."

There is a straightforward way to bypass the problem of family clusters in a case-control study, namely, to look at only unrelated individuals. In the present case, this would involve, in the first instance, examining the set of respondents who do not have siblings. Using a standard logistic regression for the MAOA- $\mu$ VNTR data (restricted to males, including controls for race and age), we find an odds ratio of 1.13 and a $p$-value of $.645(n=235)$. If we enlarge the data set to include homozygous females, we find an odds ratio of 1.16 and a $p$-value of $.518(n=348)$. Neither approaches a significant finding. Similarly, the logistic model of 5HTTLPR interaction using only unrelated respondents (including FD's controls) yields an odds ratio of 1.67 and a $p$-value of $.126(n=472)$.

Of course, we can substantially increase the number of unrelated individuals available for consideration by sampling from family clusters. Doing so more than triples the amount of family-independent information available for analysis. Moreover, because almost all family clusters contain only two individuals, the loss of information and statistical power caused by sampling one person per family is comparatively small when considered against the ideal amount of information that two-person family clusters could provide if the latent effects of relatedness were properly captured. Indeed, the most defensible statistical approach for analyzing the genetic subsample of the Add Health data is to (1) randomly sample from family clusters and (2) use a logistic regression to investigate associations among the resulting population of unrelated individuals. By repeating this process of random sampling and analysis, we can arrive at a distribution of regression coefficients and $p$-values that provides the most defensible estimate of the true values for the population.

Accordingly, for our analysis, we randomly sampled one individual from each family ID to construct a subset of unrelated individuals. We did so 500 times to create 500 different subsets. We analyzed each of these subsets using logistic regression with FD's controls and then averaged the 500 results to arrive at an estimate of the true odds ratio. The results are presented in Table 1, columns F-J. In brief, restricting analysis to unrelated individuals yields results that are not significant at the .05 level in any of the models.

\section{BROADER ISSUES IN GENETICS}

According to many top researchers in the field, the science of genetics is undergoing a paradigm shift (Dear 2009; Gressler and Haslberger 2010; McClellan and King 2010; Ooi and Wood 2008; Petronis 2010;
Sgaramella and Astolfi 2010; Whitelaw and Whitelaw 2006). Consider the following:

- Genes do not regulate the extent to which they are capable of being transcribed in any obvious, unidirectional manner. Rather, the extent to which a gene can be transcribed is controlled by the epigenome, the complex biochemical regulatory system that turns genes on and off, is environmentally reponsive, and can influence phenotype via environmentally induced changes to gene transcribability ${ }^{8}$ with no changes to the DNA sequence (Jirtle and Skinner 2007). As neuroscientist Mark Mehler (2008, 602) notes in regard to the epigenome and epigenomics, "We are in the midst of a revolution in the genomic sciences that will forever change the way we view biology and medicine, particularly with respect to brain form, function, development, evolution, plasticity, neurological disease pathogenesis and neural regenerative potential." CGA studies depend on the assumption that the presence of a particular allele entails that it is turned on; that is, it is capable of being transcribed in a manner that is associated with that allele. Hence, the same two polymorphisms in any two given individuals (e.g., the long MAOA gene) will have the same capacity to be transcribed in the same manner. We can no longer assume, however, that the presence of a particular allele entails that it is capable of being transcribed in the manner associated with that allele, because it may be epigenetically silenced.

- Human possess fewer genes than corn. The discovery that the human genome contains $\sim 25-30,000$ genes, as compared to more than 32,000 genes in maize (Schnable et al. 2009), necessitated a rethinking of the assumption that for every protein there is a specific gene and that each gene contains the instructions for making just one protein, inasmuch as there are likely more than one million proteins in the human organism (Jensen 2004). Alternative splicing refers to the process whereby one and the same gene can be used (by the cell) to produce variant forms of a protein, called isoforms (Nilsen and Graveley 2010). Hence, a single gene can code for multiple proteins, something that is estimated to occur in $90 \%$ of all human genes. We cannot equate a particular allele straightforwardly with the production of a particular form of a protein and from that with the production of a particular physiological effect and corresponding phenotype.

- Once considered the paragon of stability, DNA is subject to all manner of transformation. For

\footnotetext{
8 We use the word "transcribability" in place of the more common "expressivity" for the following reason: Genes do not "express themselves" in response to environmental signals and "produce" more or less of an RNA or protein as a "response." Hence, genes do not exhibit expressivity. Rather, the cell "expresses itself," mobilizing numerous responses to internal and external environmental stimuli that enable it to produce more of a given RNA or protein that is coded for in one of its genes. On its own, DNA is incapable of producing or expressing anything. All the biochemical machinery necessary for transcribing DNA is external to it.
} 
example, retrotransposons or "jumping genes" comprise $45 \%$ of the human genome, move about the genome by a copy-and-paste mechanism changing DNA content and structure, are regulated by the epigenome (and hence are potentially environmentally responsive), and appear to be particularly prevalent in the human brain (Coufal et al. 2009). Once dismissed as "junk DNA" and "selfish parasites" (Dawkins 2006), retrotransposons are now deemed an essential component of normal human development and functioning (Walters, Kugel, and Goodrich 2009).

- Until recently, single nucleotide polymorphisms (SNPs) were thought to be the predominant form of genomic variation and to account for most normal and abnormal phenotypic variation in humans. A recent and important development in human molecular genetics has been the discovery of the ubiquitousness of a variety of structural variations (SVs) in DNA-deletions, insertions, duplications, and inversions-as well as more complex multisite variants of varying sizes that change the chromosomal architecture (Redon et al. 2006). It is now apparent that human genomes differ more as a consequence of structural variation than of differences in single nucleotides (i.e., single nucleotide polymorphisms), and there is growing evidence for the importance of SVs for variation in human phenotypes (Alkan, Coe, and Eichler 2011).

Although all of these developments have important implications for gene association studies, we focus here on one that is particularly relevant: the realization that most human traits with a genetic component are influenced by a vast number of genes of small effect. This calls into question the underlying assumption of CGA studies. At the same time, it makes the proliferation of CGA studies involving the same genotype and a range of phenotypes particularly problematic.

\section{Complexity of the Genotype-Phenotype Relationship}

Multifactorialism. Reproducibility has long been considered a key part of the scientific method. In epidemiology, where variable conditions are the rule, the repeated observation of associations between covariates by different investigative teams, in different populations, using different designs and methods, is typically taken as evidence that the association is not an artifact (Kraft 2008). Most gene association studies (both candidate and genome wide) fail to be consistently replicated. For example, for the best known associations for MAOA- $\mu$ VNTR and 5-HTTLPR derived from CGA studies, there are multiple nonconfirming studies including, in the case of MAOA- $\mu$ VNTR, studies reporting no association with "antisocial" behavior (Huizinga et al. 2006; Prichard et al. 2008; Young et al. 2006) and, in the case of 5-HTTLPR, no association with depression (Chipman et al. 2007; Middeldorp et al 2007; Power et al. 2010; see Table 2). A recent comprehensive meta- analysis of association studies that linked 5-HTTLPR, stressful life events, and risk of depression, published in the Journal of the American Medical Association, reached this conclusion (Risch et al. 2009, 2469):

The results of this meta-analysis clearly demonstrate that stressful life events have a potent relationship with the risk of depression, an association that has been one of the most widely studied environmental factors for a range of mental disorders. Addition of the serotonin transporter genotype did not improve the prediction of risk of depression beyond that associated with exposure to negative life events.

Although there have been numerous attempts to explain ongoing failures of consistent replication (or, in some cases, any replication), the answer most likely concerns the nature of the traits for which genetic predictors are sought. Most human traits with a genetic component are multifactorial (or complex): They are polygenic, involving the biochemical products of hundreds and even thousands of genes interacting with each other, the epigenome, and the environment in complex ways. Consider height, for example. Height is a highly heritable trait: $80 \%$ of the variation in height in a given population at a given time is attributable to genetic factors. A new, exceptionally large study involving full genome scans (genome-wide association [GWA] studies) of more than 180,000 individuals identified 180 genomic regions that influence adult height (Lango Allen et al. 2010). However, the variants on these 180 genes, considered together, explain only $10 \%$ of the heritable phenotypic variation in height in a given population, with no variant explaining more than a tiny fraction of a percent of variation.

The situation is no different in regard to behavioral phenotypes. Commenting on the failure of GWA studies to identify polymorphisms associated with behavioral phenotypes (as well as the failure of GWA studies to confirm the results of CGA studies), Plomin and Davis $(2009,63)$ note, "GWA studies suggest that for most complex traits and common disorders genetic effects are much smaller than previously considered... . This finding [of small genetic effects] implies that hundreds of genes are responsible for the heritability of behavioural problems in childhood, and that it will be difficult to identify these genes of small effect."

A good example of the degree of genetic complexity involved in behavioral phenotypes is provided by studies of aggression in fruit flies (Drosophila melanogaster). Researchers performed complete genome-wide gene expression and GWA scans of 40 lines of inbred Drosophila, and their analysis implicated at least 266 unique candidate genes associated with natural variation in aggressive behavior (Edwards et al. 2006, 2009a 2009b). The candidate genes were involved in a broad spectrum of biological processes, including vision, olfaction, learning and memory, and the development and function of the nervous system, as well as basic cellular processes including transcription, protein modification, and mitosis (cellular division), indicating that the single alleles involved in aggression have pleiotropic effects on 
multiple traits (i.e., the proteins for which the genes are encoded are involved in many different physiological processes). Furthermore, the findings are consistent with extensive epistasis (gene $\times$ gene interactions). At the same time, the heritability of aggressive behavior in Drosophila is relatively low $(\sim 0.1)$. Expressing the genetic and environmental variances of aggressive behavior as genetic and environmental coefficients of variation $\left(C V_{G}\right.$ and $C V_{E}$, respectively), the researchers found that $C V_{G}=23.2$ and $C V_{E}=$ 71.9. Thus, the low heritability is not due to a lack of segregating genetic variation, which is abundant, but to a high level of environmental variance (despite the fact that the scientists assumed that the environments were identical).

What all of this indicates is that most complex phenotypes that have a genetic component involve many genes of small effect size (266 and counting for variation in aggressive behavior in fruit flies). As McCrae et al. $(2010,1014)$ note, "There is growing evidence that personality traits are affected by many genes, all of which have very small effects." Hence, among common gene variants one would not expect to find single gene effects that confer a sufficiently high odds ratio to be predictive of a phenotype, such as aggression, for example. The discovery that many genes of small effect size contribute to traits known to be highly heritable (such as height) helps explain the so-called missing heritability problem (Bogardus 2009; Manolio et al. 2009; Slatkin 2009): Despite thousands of GWA and CGA studies, few genes have been reliably associated (via consistent replication) with complex phenotypes. In the words of Conrad et al. (2010), to date, GWA studies have left a "heritability void."

However, there are exceptions to the "nonpredictiveness" of single nucleotide polymorphisms (SNPs). The most obvious example concerns not SNPs, but mutations on a single gene locus that occur in $<1 \%$ of the population and are associated with so-called monogenic disorders. Monogenic disorders are inherited in a Mendelian manner (it is for this reason that they are sometimes referred to as "genetic" disorders). If the disorder is dominant, then only one mutated allele is necessary to present the disease phenotype; if the disorder is recessive, then two mutated alleles are necessary. A monogenic disorder is completely penetrant if possession of the mutated allele(s) entails that one will have the disease phenotype $100 \%$ of the time. A monogenic disorder is incompletely penetrant when the odds are $<100 \%$ that possessing the mutated alleles(s) will result in the disease (i.e., the allelic mutation is a necessary, but not sufficient, condition for the appearance of the phenotype). Highly penetrant monogenic disorders are characterized by a high probability that those with the associated alleles will develop the disease phenotype, but the probability falls short of $100 \%$. When a monogenic disorder is completely penetrant and the gene mutation known, then based on the genotype of the parents and whether the disorder is dominant or recessive, the odds that the child will inherit the disorder (the risk factor) can be calculated precisely according to the simple rules of Mendelian inheritance.
Researchers who conduct CGA studies err when they suppose that multifactorial traits exhibit a genotype-phenotype relationship analogous to that of monogenic disorders (Comings 1998; Nagel 2005; Peltonen and McKusick 2001). Furthermore, even in completely penetrant monogenic disorders, the "poster child" for Mendelian inheritance, things are turning out to be more complicated than once thought. One reason concerns the possibility of many different allelic mutations on the same gene locus being associated with the disorder; for example, more than 1,400 different mutations on the CFTR gene have been identified thus far that can cause cystic fibrosis, a recessive disorder, and different mutations have been associated with differences in disease phenotype (Bobadilla et al. 2002). More important, even when two individuals have the same mutation for the same completely penetrant monogenic disorder, it is difficult to predict phenotype on the basis of genotype alone. Consider the following three quotes from medical researchers:

An African American male infant with sickle cell disease has a devastating stroke; an African American soldier is surprised when he is informed that he has sickle cell disease. They are both homozygous for the same mutation. An Ashkenazi Jewish woman with Gaucher disease has a huge spleen and severe thrombocytopenia; her older brother, homozygous for the same... mutation, is found on routine examination to have a barely palpable spleen tip.... Such siblings must surely be carrying the same 2 disease-producing alleles. With the advent of sequence analysis of genes, the great extent of phenotype variation in patients with the same genotype has come to be more fully appreciated, but understanding of why it occurs continues to be meager (Beutler 2001, 2597).

The dogma in molecular genetics until the 1990s was that genotype would predict phenotype. We thought that once we cloned and characterized the gene, then the nature of the mutation in the gene would specify the individual's phenotype... This concept celebrated reductionism. However, nature had not informed the patients and their biology of this belief system. Not only could we not predict phenotype for genotype for $\mathrm{GK}$ and $\mathrm{AHC}$ [ two monogenic disorders], similar observations were being made by others for many rare [monogenic] genetic disorders (McCabe and McCabe 2006, 160).

This indicates that the phenotypes of "single-gene" disorders are in fact complex traits (Nagel 2005; Weatherall 2000), influenced by multiple genetic, epigenetic, and environmental factors:

One promise of molecular genetics for many of us was that a detailed knowledge of mutant alleles would permit accurate prediction of prognosis and better selection of therapeutic strategies for Mendelian disorders. This presumed predictive promise was naïve and was based on a reductionist view of genotype-phenotype correlations, i.e., that a refined and specific knowledge of a mutation's impact on protein structure and function would permit extrapolation to the phenotype of the intact organism. The reality of molecular genetics, however, is that for many diseases only a subset of mutations reliably predicts phenotype. This lack of genotype-phenotype correlation 
for many Mendelian disorders shows us that the clinical phenotypes of "simple" Mendelian disorders are complex traits (Dipple, Phelan, and McCabe 2001, 45).

Keep in mind that the preceding three quotes concern the difficulty of predicting phenotype on the basis of genotype alone in disorders associated with mutations on a single gene. For most normal, heritable human traits (such as height), thousands of genes are implicated. Among the few reliably reproduced associations between an SNP and a given phenotype of such a magnitude that the SNP can be called a risk factor are the following: the E4 variant of the apolipoprotein E gene, ApoE, which increases the risk of Alzheimer's disease; the association of an amino acid substitution in the complement factor $\mathrm{H}$ gene, $\mathrm{CFH}$, with age-related macular degeneration; and a variant in the LOXL1 gene with exfoliation glaucoma, a common form of age-related blindness (Need and Goldstein 2010). In the case of the latter two, however, the SNPs are so prevalent in the population that they lack predictive value. Why these are exceptions is not entirely clear, although it may be an indication that they are oligogenic disorders involving polymorphisms on a small number of genes and hence are more akin to monogenic disorders than to most human traits. As such, they are exceptions that prove the rule.

Overabundance and Serendipity. The problem of overabundance concerns the large number of diverse phenotypes that have been associated with the same two sets of polymorphisms of MAOA (MAOA$\mu$ VNTR) and 5-HTT (5-HTTLPR). Table 2 is only a sampling (by no means complete) of the wide array of traits that have purportedly been associated with high, low, and intermediate MAOA- $\mu$ VNTR, and long and short 5-HTTLPR, along with a sample of studies finding no association with the phenotype. The table also includes a sampling of phenotypes that have been associated with polymorphisms of two other genes, the dopamine D2 receptor gene (DRD2) and the dopamine D4 receptor gene (DRD4), as well as studies showing no association. These four genes represent half of the genes for which there are genotypic data in the Add Health data set.

A list such as that in Table 2 raises numerous questions, but we mention only two here. First, how is it possible that the same polymorphisms of the same gene could simultaneously predict (or be risk factors for) so many different phenotypes (even when, as is sometimes the case, a specific $\mathrm{G} \times \mathrm{E}$ or $\mathrm{G} \times \mathrm{G}($ gene $\times$ gene) interaction is proposed)? A common response to the problem of overabundance is to evoke the concept of an endophenotype. An endophenotype is defined as an intermediate trait or an internal phenotype that lies intermediate between the genotype and phenotype (Gottesman and Shields 1973). The idea is that the endophenotype, which is more "elementary" than the phenotype, can give rise to an array of phenotypes (because of interacting genetic or environmental factors) that all share something with the more primary endophenotype. Furthermore, the genetic basis of en- dophenotypes is assumed to be less complicated than the phenotypes to which they give rise, to involve fewer genes, and to be more "direct" and "deterministic" (Flint and Munafo 2007).

It is beyond the scope of this article to consider the cogency of the concept of an endophenotype, other than to note the following: Psychologists created this concept to give plausibility to the idea that a single polymorphism could in fact predict, or be a risk factor for, a wide array of multifactorial traits. In other words, it has been embraced in large part to justify the cogency of undertaking gene association studies and of their results. However, it is a concept that lacks any independent justification either genetically or biologically; for example, if more than 266 genes are involved in aggression in fruit flies, what is the endophenotype that "underlies" aggression and can be predicted by a single gene? Furthermore, if it is proposed that the high and low polymorphisms of MAOA- $\mu$ VNTR are associated with an endophenotype, what more elementary phenotype underlies credit card debt, bone mineral density, schizophrenia, sudden infant death syndrome, conscientiousness, and autism? Or in the case of long and short 5-HTT, what more elementary phenotype unites maternal sensitivity, premature ejaculation, irritable bowel syndrome, schizophrenia, periodontal disease, and voting?

The genes coded for MAOA and 5-HTT are two genes among an estimated 25,000-30,000 genes. The MAOA- $\mu$ VNTR and 5-HTTLPR polymorphisms of these two genes are several polymorphisms out of anywhere from 3-15 million possible polymorphisms throughout the human genome, and up to $30^{10}$ mutations (Cotton and Horaitis 2002). Thus far, 299 SNPs have been identified on the MAOA gene alone ${ }^{9}$ and 513 on the 5 -HTT gene, ${ }^{10}$ as well as several structural variations on both genes, and there is little doubt that more polymorphisms and common structural variations are still to be discovered on both of these genes. Yet of 299 polymorphisms (and counting) in the case of MAOA, and 513 in the case of 5-HTT, a handful in either gene appear to be in some way predictive of (or associated with) an astonishing array of human behaviors (as well as nonbehavioral phenotypes).

This brings us to the second question, which concerns the problem of serendipity. Consider that the polymorphisms of MAOA- $\mu$ VNTR and 5-HTTLPR are the only polymorphisms for these two genes for which there are data in a large data set such as Add Health and that MAOA and 5-HTT are two out of the eight genes in total for which there are genotypic data. What is the likelihood that these same polymorphisms on these same genes will conveniently turn out to be the genetic key to so much human behavior? These eight genes have been associated in studies using the Add Health data with a wide array of phenotypes, either directly or via a proposed $\mathrm{G} \times \mathrm{E}$ or $\mathrm{G} \times \mathrm{G}$ interaction.

\footnotetext{
${ }^{9}$ Genecards, MAOA, http://www.genecards.org/cgibin/carddisp.pl? gene $=$ MAOA\&search $=$ maoa.

10 Genecards, 5-HTT, http://www.genecards.org/cgi-bin/carddisp. $\mathrm{pl}$ ?gene $=$ SLC6A4\&search $=5$-htt.
} 
As was the case with MAOA- $\mu$ VNTR and 5-HTTLPR, the same polymorphisms of the same gene have also been associated with an array of disparate phenotypes.

For example, DRD2 Taq1A, an SNP of the dopamine $\mathrm{D} 2$ receptor gene, has been associated in studies using Add Health data with the following behaviors: serious and violent delinquency among males (Guo, Roettger, and Shih 2007); "homophily," a desire for friends who also have the DRD2 Taq1A polymorphism (Fowler, Settle, and Christakis 2011); the number of vaginal sexual partners in the previous year among males (Halpern et al. 2007); whether or not an offender has been violently victimized (Vaske et al. 2009a); depression (Guo and Tillman 2009); victimization among white males who have delinquent peers (Beaver et al. 2007a); partisanship (Dawes and Fowler 2009); contraceptive use (Daw and Guo 2011); the intergenerational transmission of parenting (Beaver and Belsky n.d.); resiliency to victimization (Beaver et al. 2011); polydrug use among males who exhibit maternal withdrawal (Vaughn et al. 2009); continuation of education beyond secondary school among males who have mentors who are teachers (Shanahan et al. 2007); frequency of alcohol consumption among young adults (excluding adolescents; Guo, Wilhelmsen, and Hamilton 2007); intake of high-calorie nonsweet food among severely depressed males (Agurs-Collins and Fuemmeler 2011); five antisocial phenotypes among African American females who have a criminal father (DeLisi et al. 2009); academic achievement during middle and high school (Beaver et al. 2010); smoking among young adults who report at least six inattentive symptoms (McClernon et al. 2008); verbal skills among whites (Beaver et al. 2010); continuation of education beyond secondary school among males who have high parental socioeconomic status, high parental involvement in school, or attend high-quality schools (Shanahan et al. 2008); conduct disorder among males who also possess the DRD4 Exon 3 VNTR polymorphism (Beaver et al. 2007b); self-esteem (Jonassaint et al. 2008); and the depressive effects of violent victimization on African American females (Vaske et al. 2009a).

In studies other than those using the Add Health data, the DRD2 Taq1A polymorphism has also been associated with many of the same phenotypes that have been associated with MAOA- $\mu$ VNTR and 5HTTLPR: smoking (Zuo et al. 2009); novelty seeking, harm avoidance, and persistence (Nyman et al. 2009); cooperativeness (Walter et al. 2011); obesity, anorexia nervosa, and bulimia (Nisoli et al. 2007); Parkinson's disease (Grevle et al. 2000); alcoholism (Berggren et al. 2006); ADHD (Paclt et al. 2010); drug addiction (Shahmoradgoli Najafabadi et al. 2005); suicide (Suda et al. 2009); schizophrenia (Stöber et al. 1999); bipolar disorder (Squassina et al. 2011); post-traumatic stress disorder (Comings, Muhleman, and Gysin 1996); and Tourette syndrome (Lee et al. 2005). It has also been associated with phenotypes such as "Eros," "a loving style characterized by a tendency to develop intense emotional experiences based on the physical attraction to the partner" (Emanuele et al. 2007); susceptibility to confirmation bias (Doll, Hutchison, and Frank 2011); caffeine-induced anxiety (Childs et al. 2008 ; and prolactin (a hormone involved in lactation) secretion induced by antipsychotics in healthy volunteers (LopezRodriguez et al. 2011).

The Third Wave of the Add Health study contains well over a thousand survey questions covering a vast range of behaviors. If one considers the entirety of the Add Health data sets, many thousands of behavioral variables are associated with each individual, and if one introduces interaction terms and multivariable controls, the quantity of variables available for genetic "prediction" could quickly surpass ten thousand. The standard statistical criterion for any individual study of a gene-behavior correlation is significance at an alpha level of .05. The problem with this criterion becomes clear if researchers embark on what collectively amounts to a blind fishing expedition in search of correlations between a handful of candidate genes and a wide array of behaviors.

It is particularly problematic given that the soughtafter correlations are not between particular genes and particular phenotypes, but between particular alleles and particular phenotypes. The alleles may be grouped into two categories (e.g., long and short 5-HTTLPR) or three categories (e.g., high, intermediate, and low MAOA- $\mu$ VNTR), or as in the case of the DRD4 gene, direct associations may be reported between any of the nine single alleles concerning which there is information in a data set such as Add Health and a given phenotype; for example, those who have at least one copy of the number 3 (out of 9) repeat $(\mathrm{R})$ allele of the DRD4 gene are more likely to have sexual intercourse at a younger age (Guo and Tong 2006). Or associations may be reported between any combination of these alleles and a given phenotype (e.g., those with the genotype DRD4 2R/2R are more likely to exhibit depression [Guo and Tillman 2009]); or between any combination of alleles of a given gene and the alleles of another gene $(\mathrm{G} \times \mathrm{G}$ interaction); for example, those with the DRD2 Taq 1A genotypes A1/A2 or A1/A1 and at least one 7R copy of the DRD4 Exon 3 VNTR are more likely to exhibit conduct disorders (Beaver et al. 2007b). Furthermore, associations may be reported between any of these alleles and specific genders, or specific ethnicities, or specific ethnicities and genders, and these associations may involve any conceivable $\mathrm{G} \times \mathrm{E}$ interaction; for example, African American females who use marijuana and have the short/short 5-HTTLPR genotype are more likely to engage in "property offending" (Vaske et al. 2009b).

The problem of inadvertent multiple hypothesis testing has long been understood and is something to which researchers must pay close attention. The most straightforward way to deal with this problem is to employ the so-called Bonferroni correction: dividing the alpha level by the number of associations tested. Doing this for ten thousand behaviors tested against one candidate gene would yield an alpha level of .000005a standard that none of the purported associations remotely approach. The Bonferroni correction is conservative, but inasmuch as Add Health data are currently being used in an intensive search for genetic 


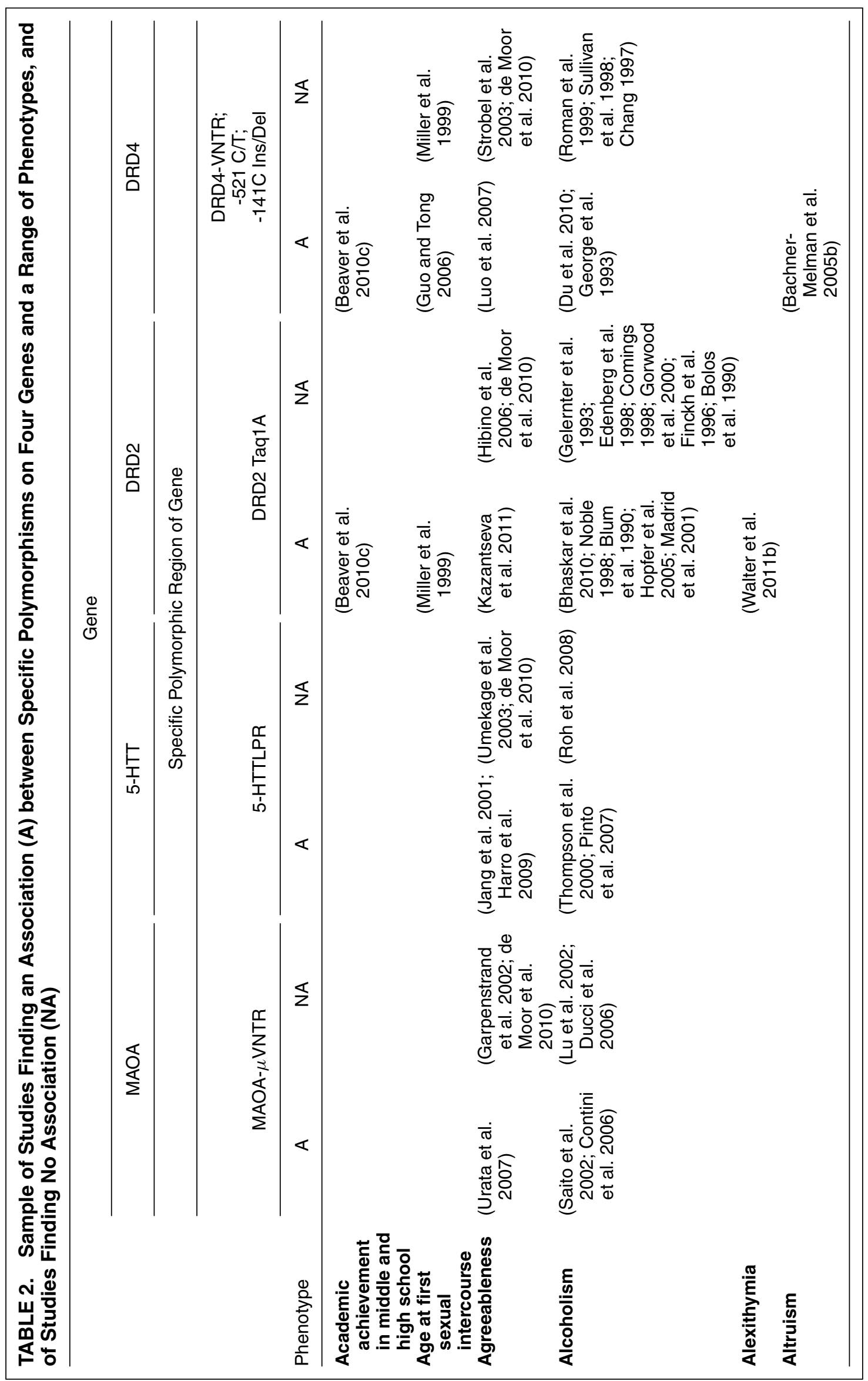




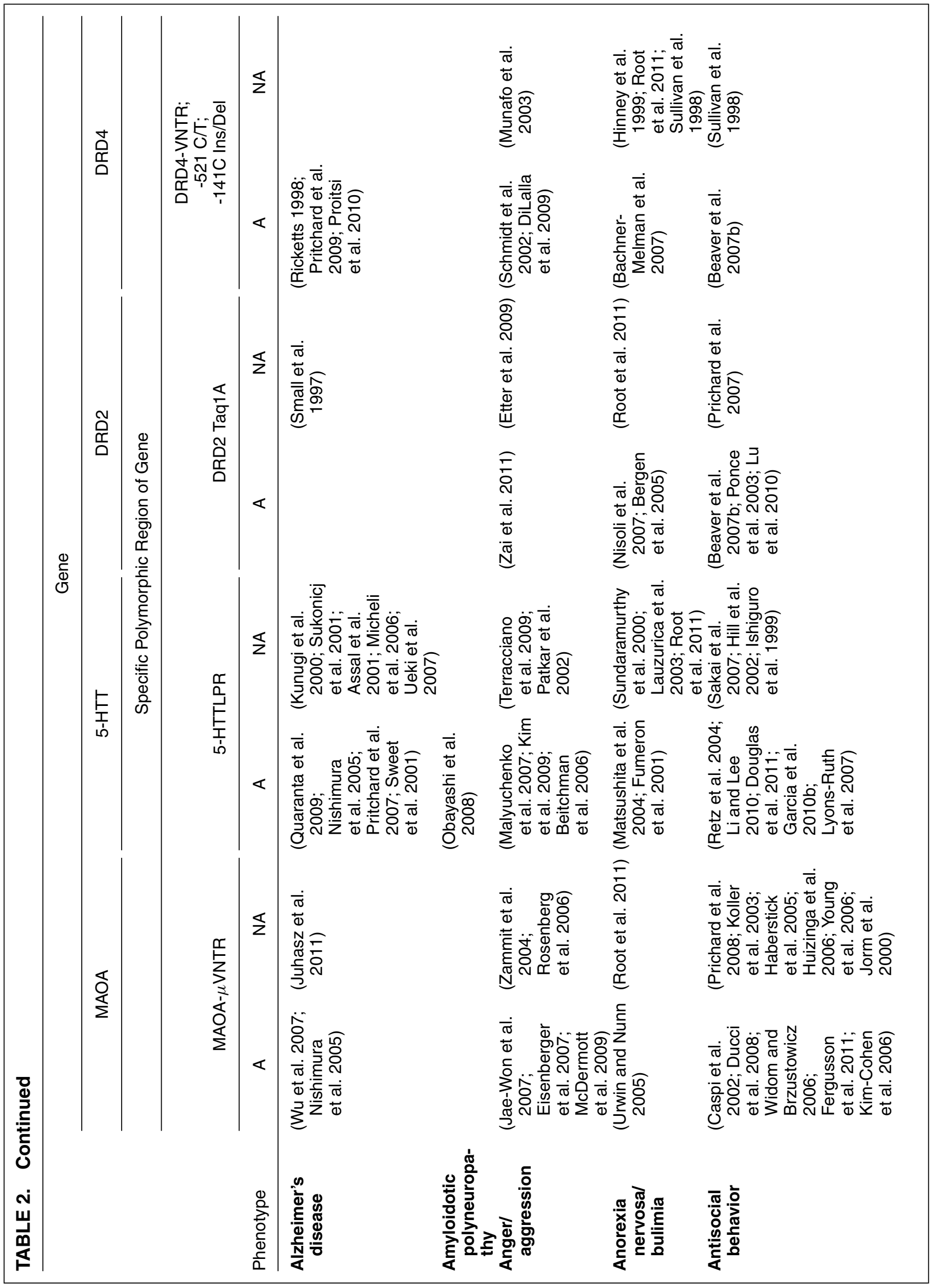




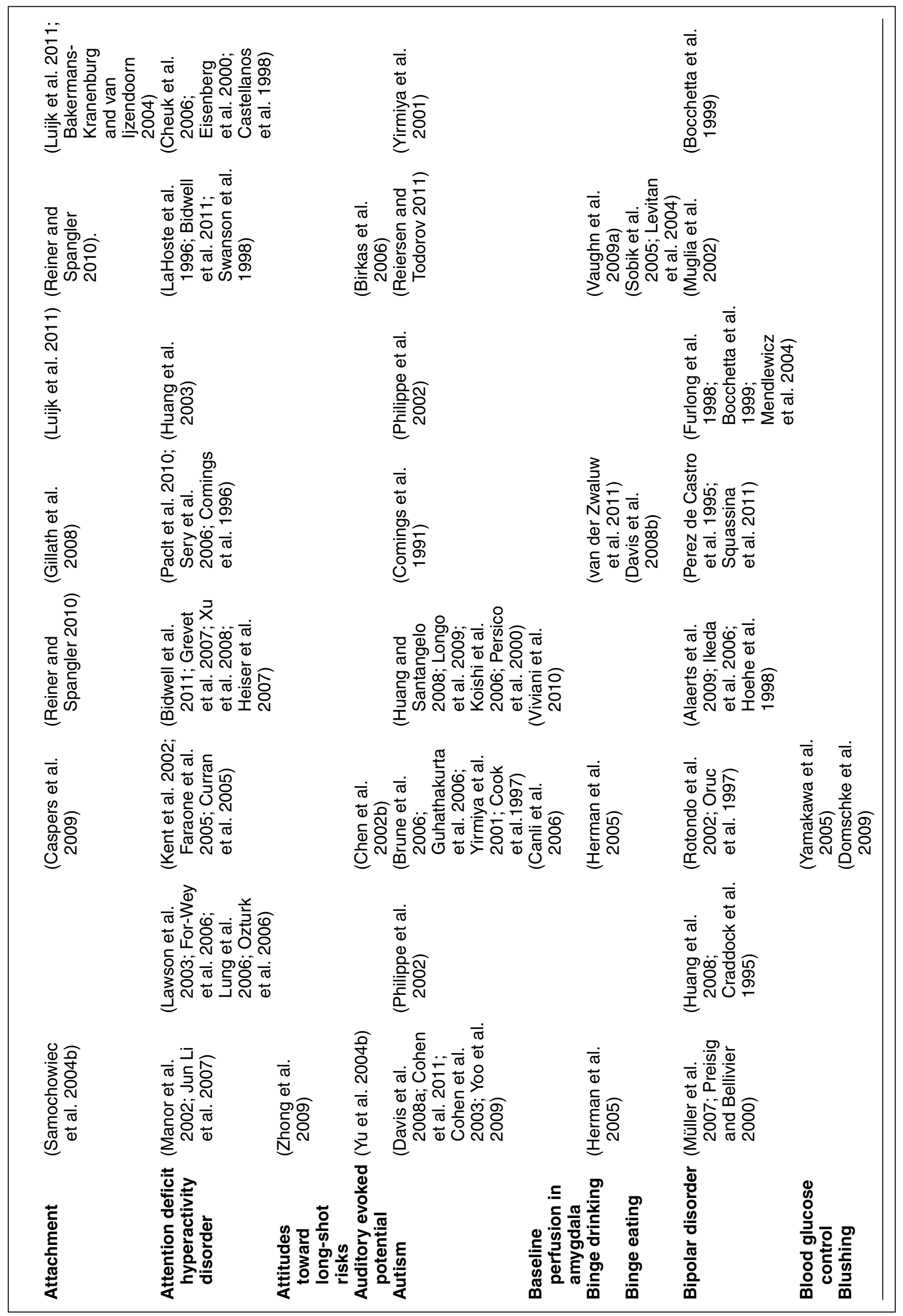




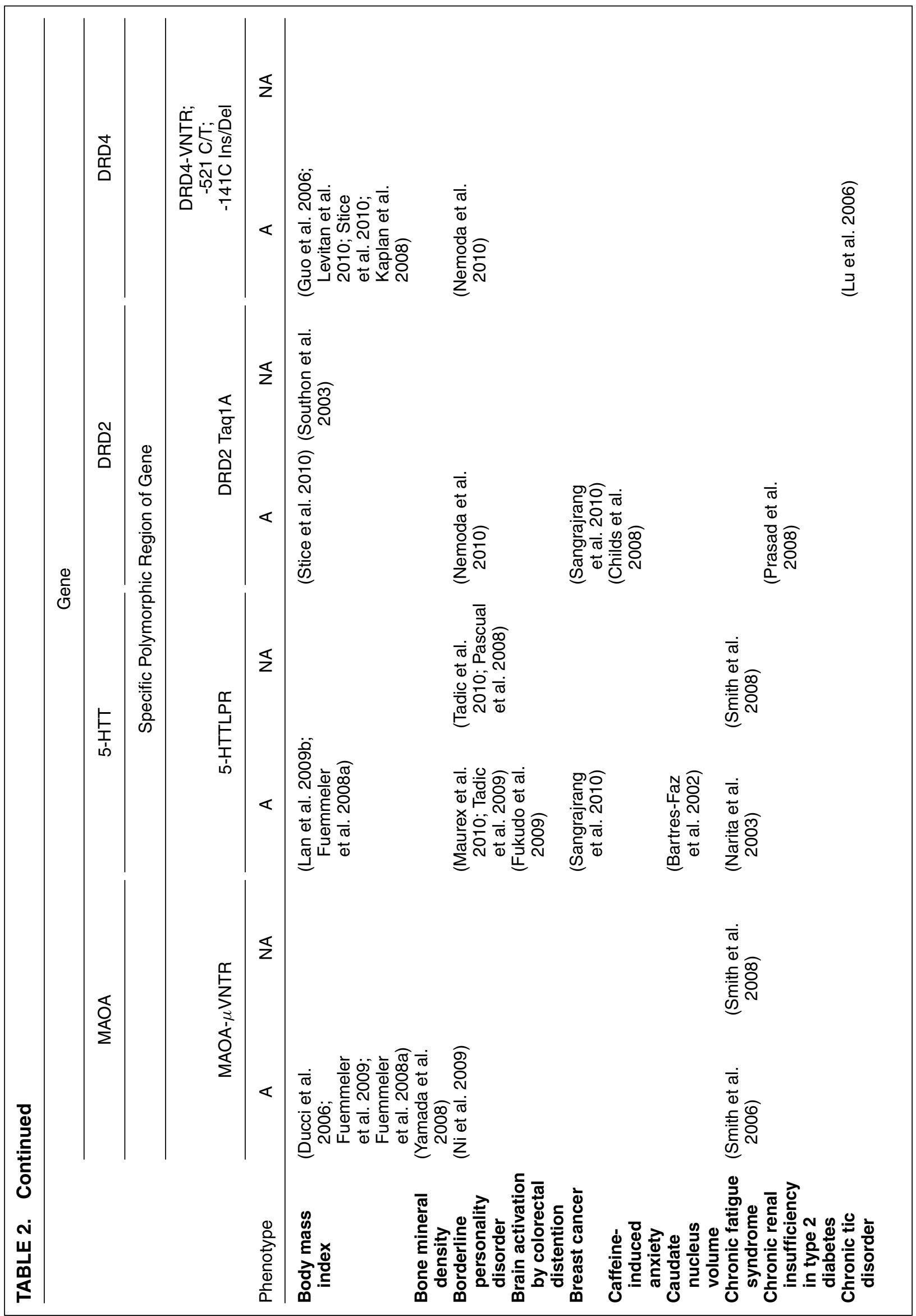




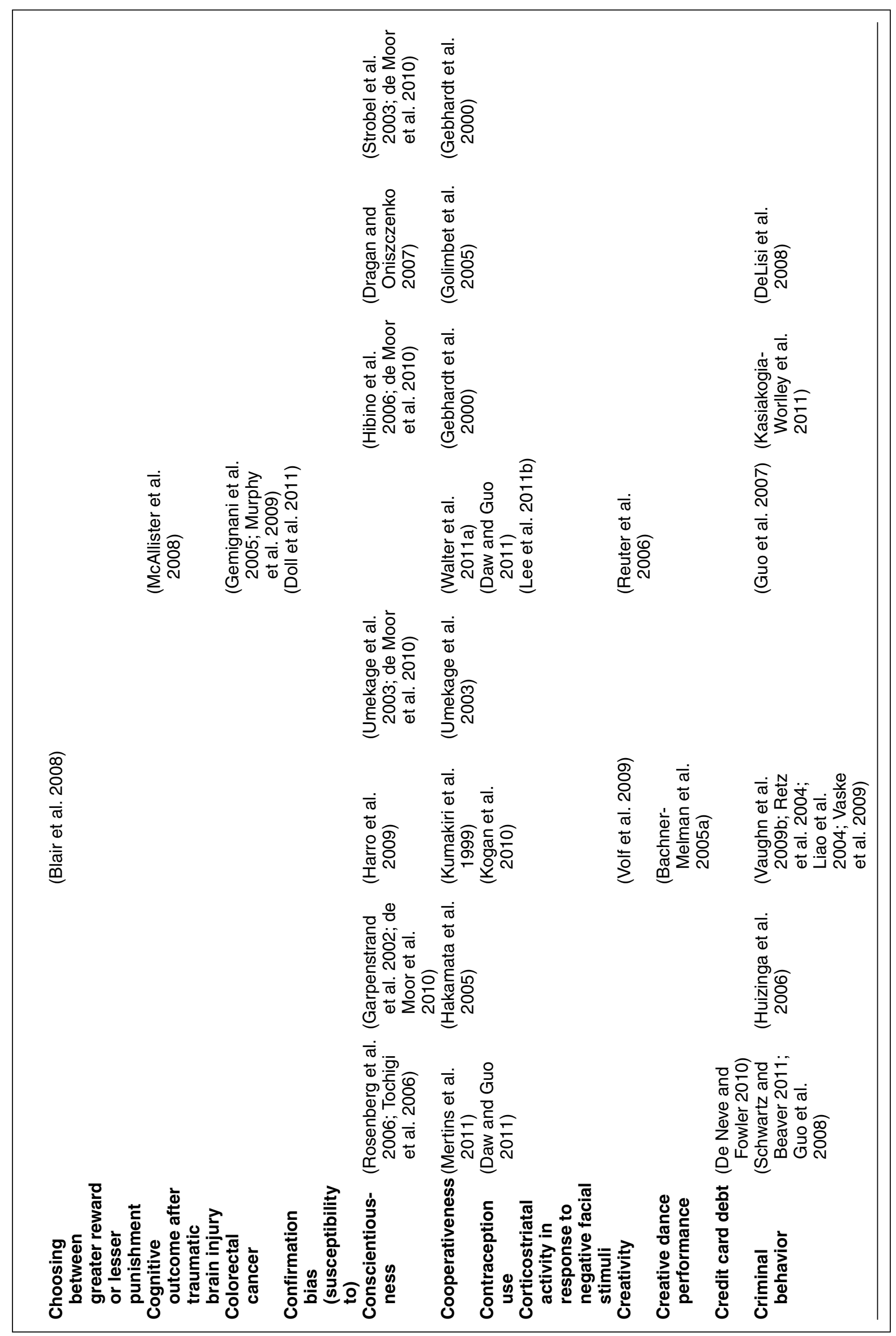




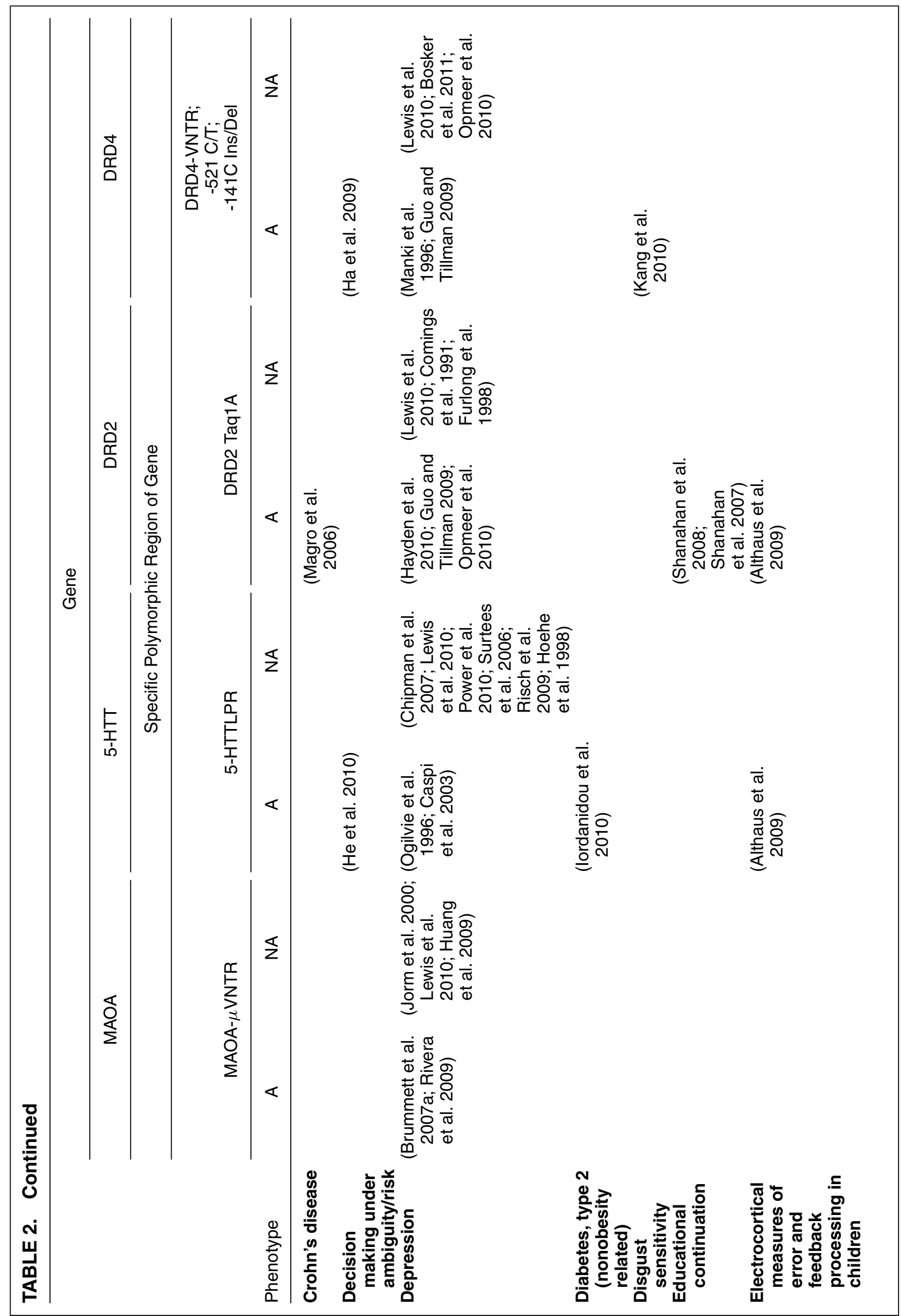




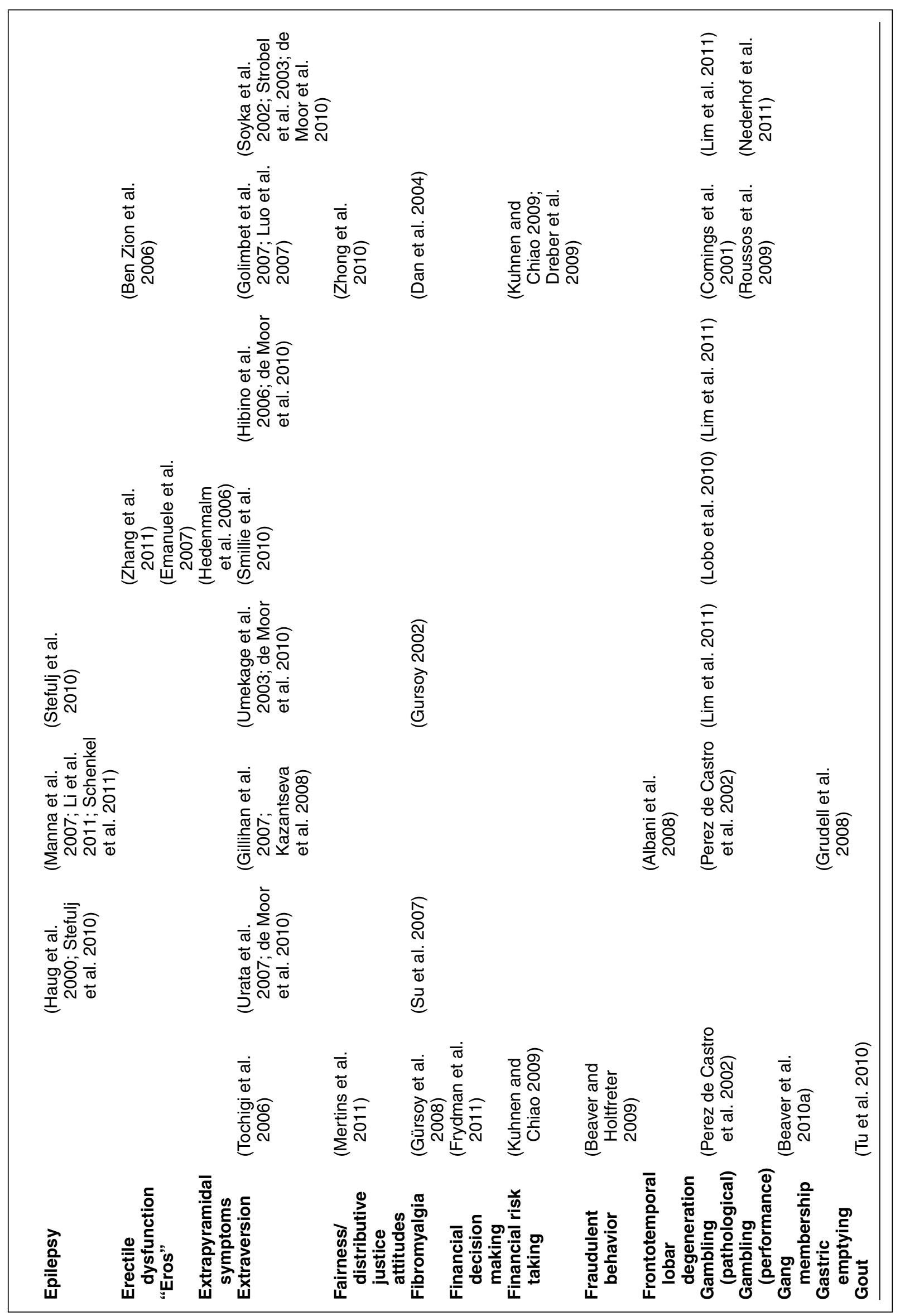




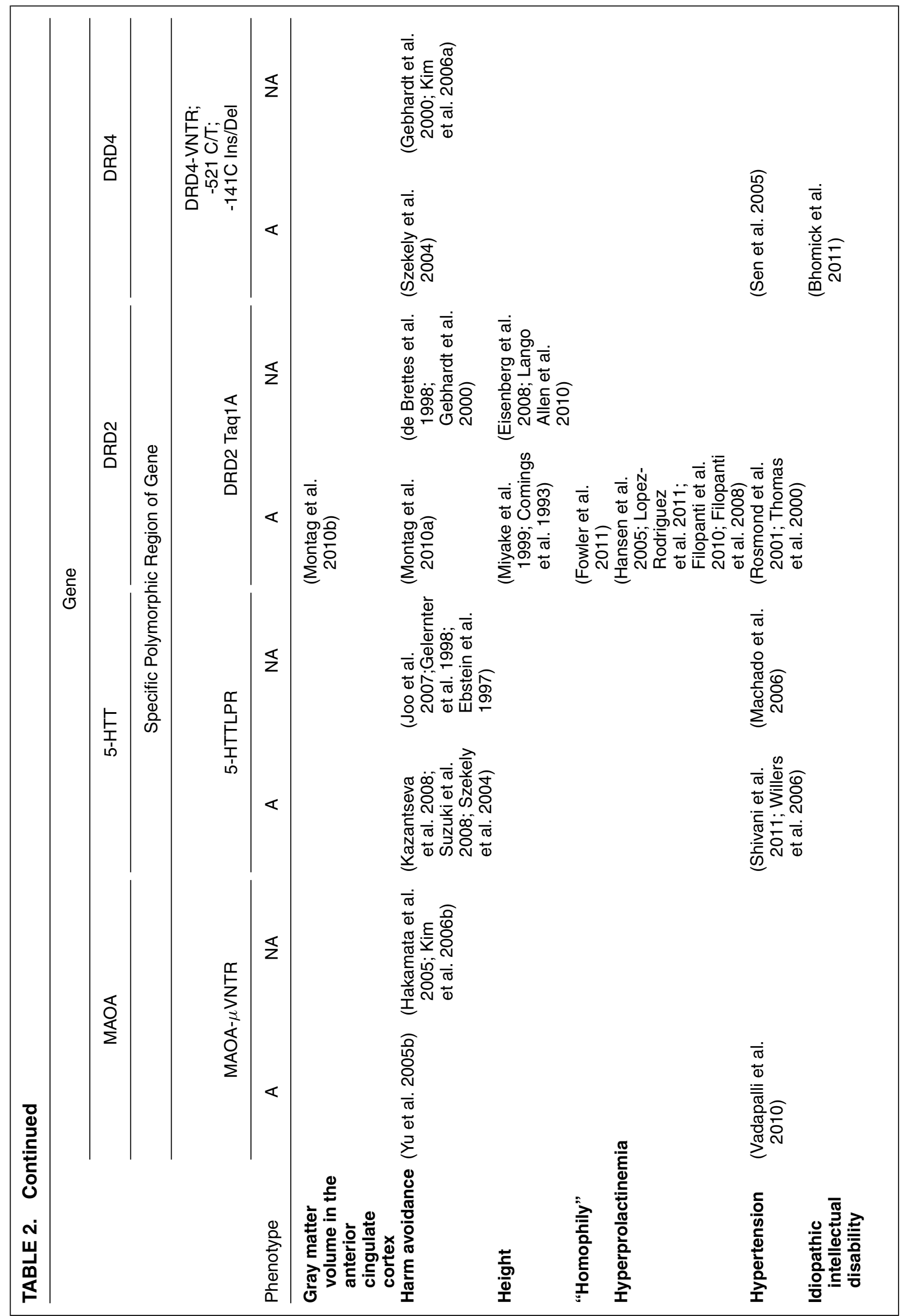




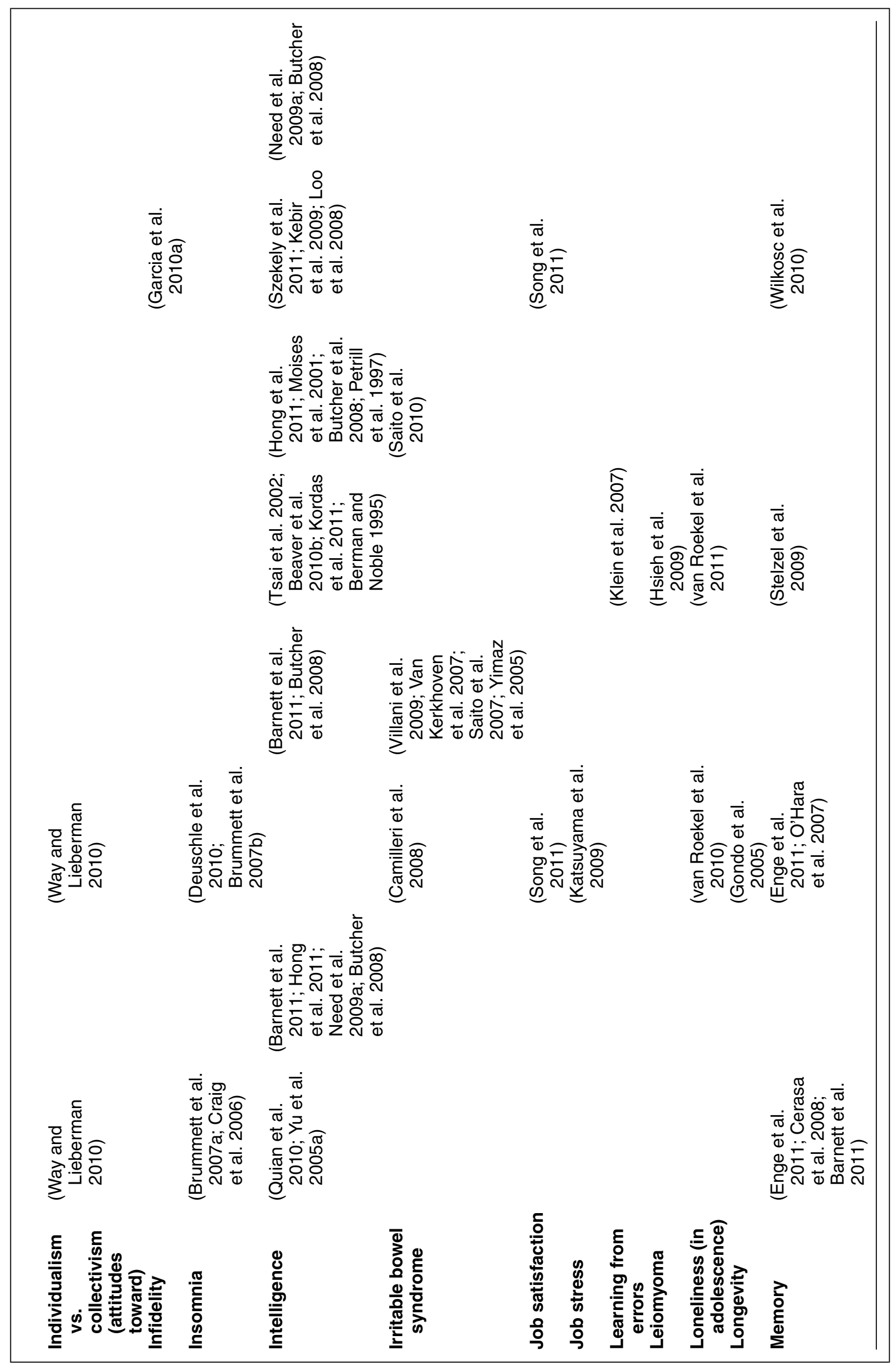




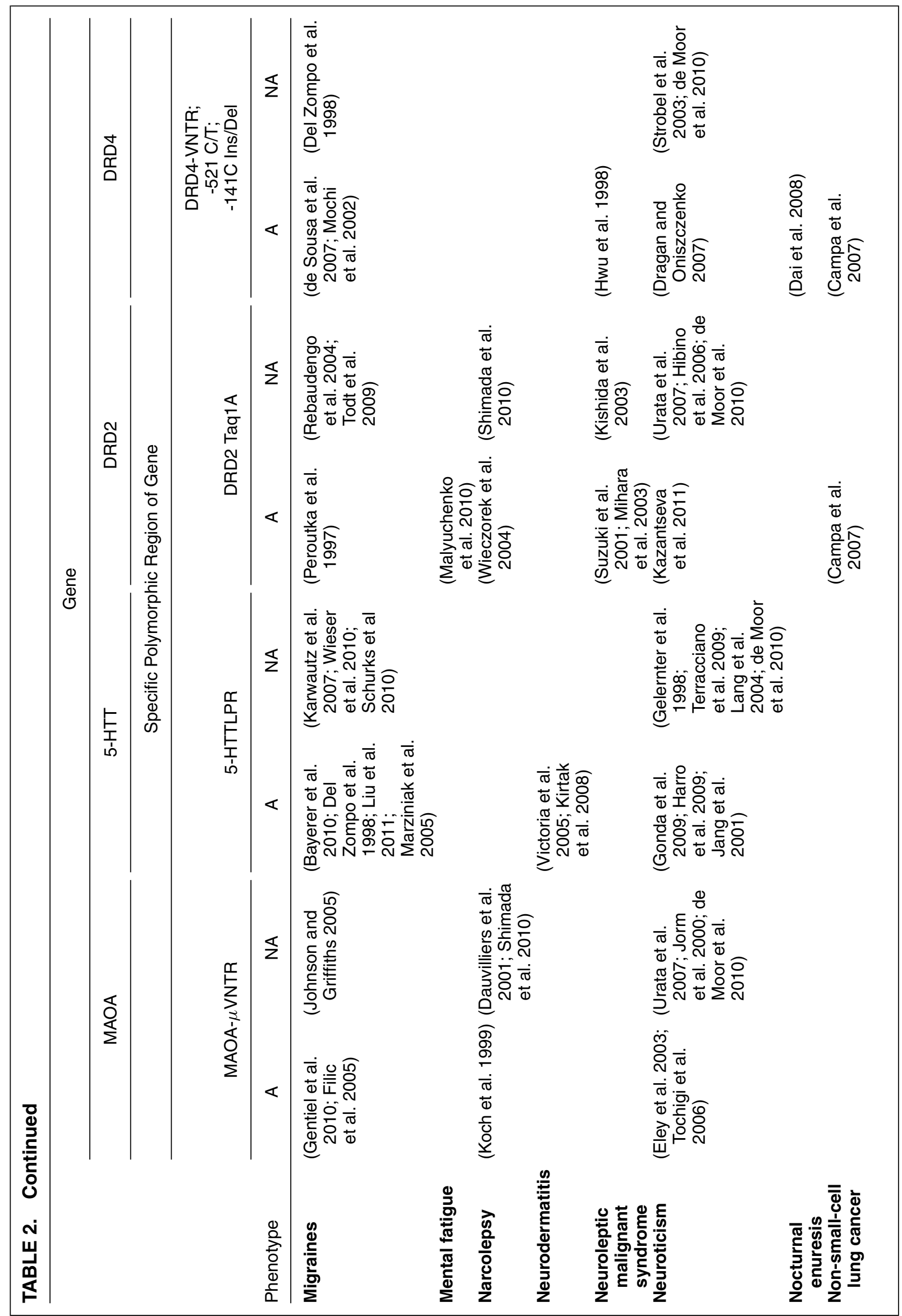




\begin{tabular}{|c|c|c|c|c|c|c|c|c|c|}
\hline 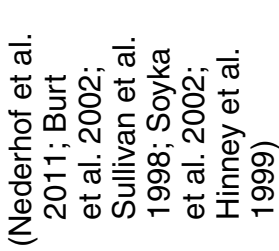 & & 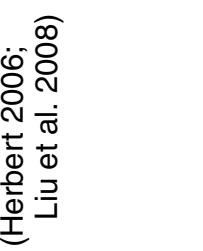 & 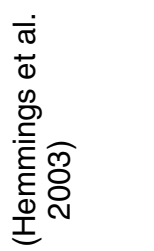 & 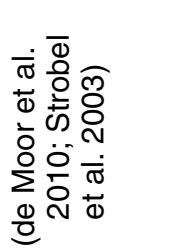 & & & 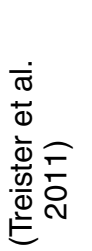 & 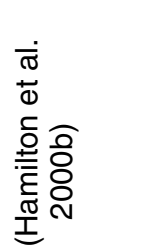 & \\
\hline 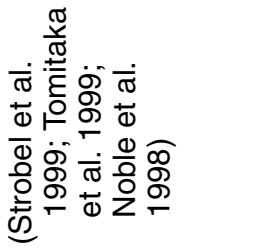 & 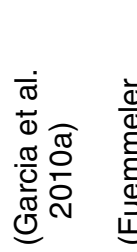 & 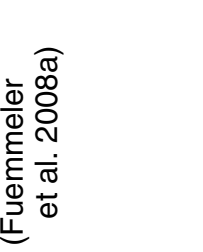 & 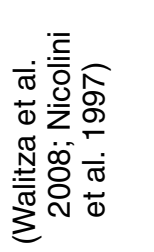 & 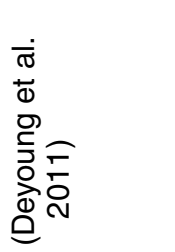 & & 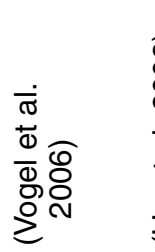 & 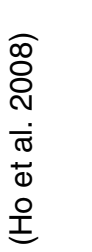 & 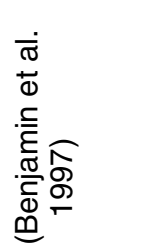 & 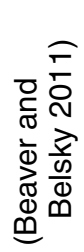 \\
\hline 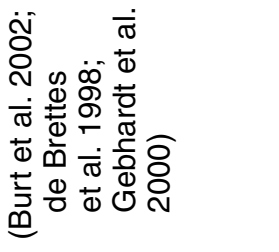 & & 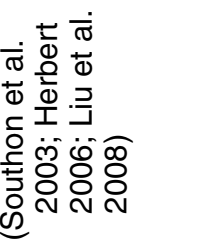 & 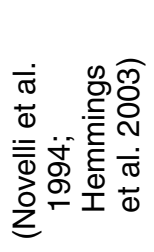 & 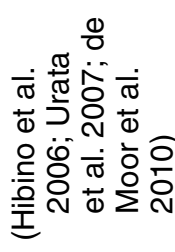 & & 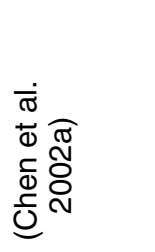 & & & \\
\hline 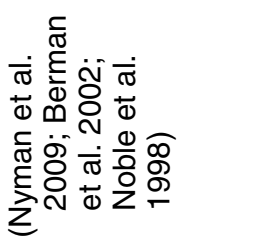 & 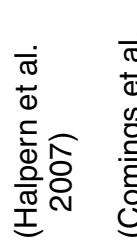 & 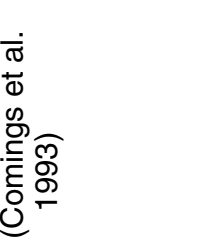 & 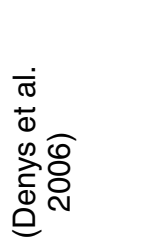 & & & 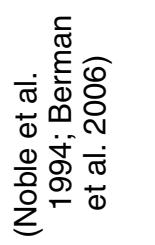 & & 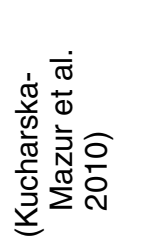 & 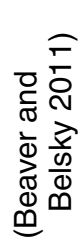 \\
\hline 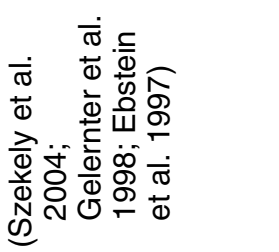 & & 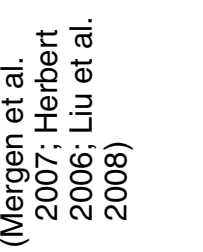 & 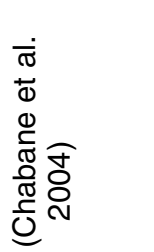 & 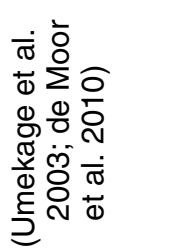 & & & 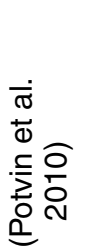 & 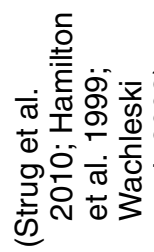 & \\
\hline 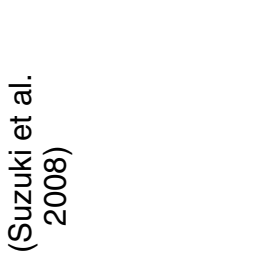 & 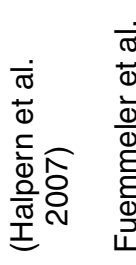 & 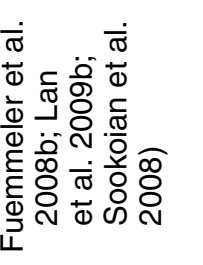 & 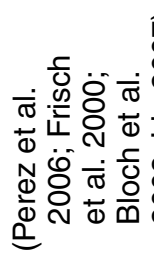 & $\begin{array}{l}\frac{\pi}{\pi} \\
\frac{0}{0} \\
0 \\
\frac{0}{2} \\
\frac{0}{1}\end{array}$ & 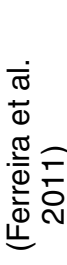 & & 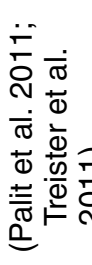 & 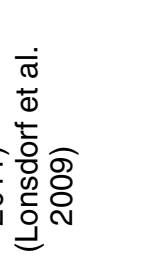 & 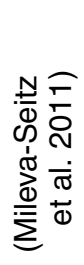 \\
\hline 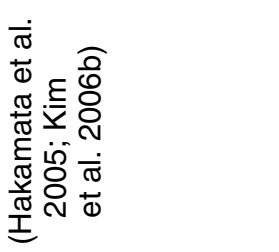 & & 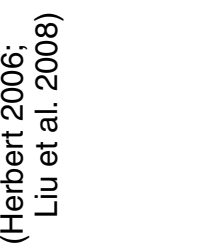 & 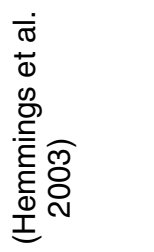 & 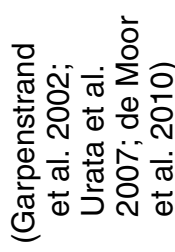 & & & 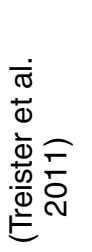 & 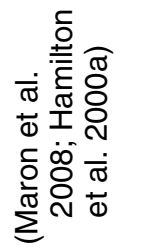 & \\
\hline 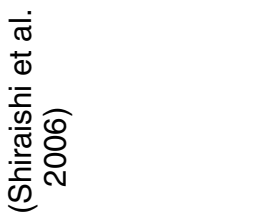 & & 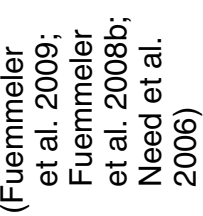 & 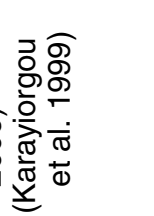 & 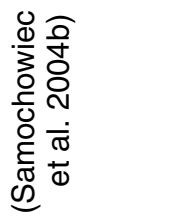 & & & 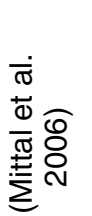 & 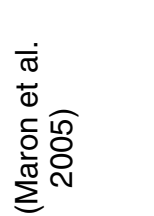 & \\
\hline 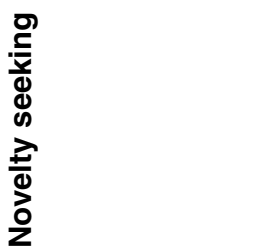 & 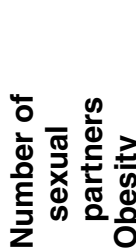 & $\begin{array}{l}\frac{7}{9} \\
\text { के } \\
0\end{array}$ & 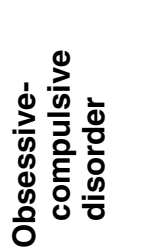 & 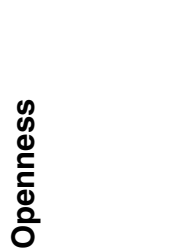 & $\begin{array}{l}\frac{0}{0} \\
\frac{0}{0} \\
\frac{0}{8} \\
\frac{d}{0} \\
\frac{0}{0}\end{array}$ & 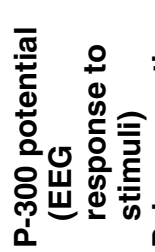 & 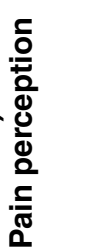 & 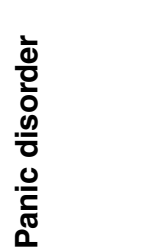 & 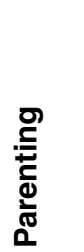 \\
\hline
\end{tabular}




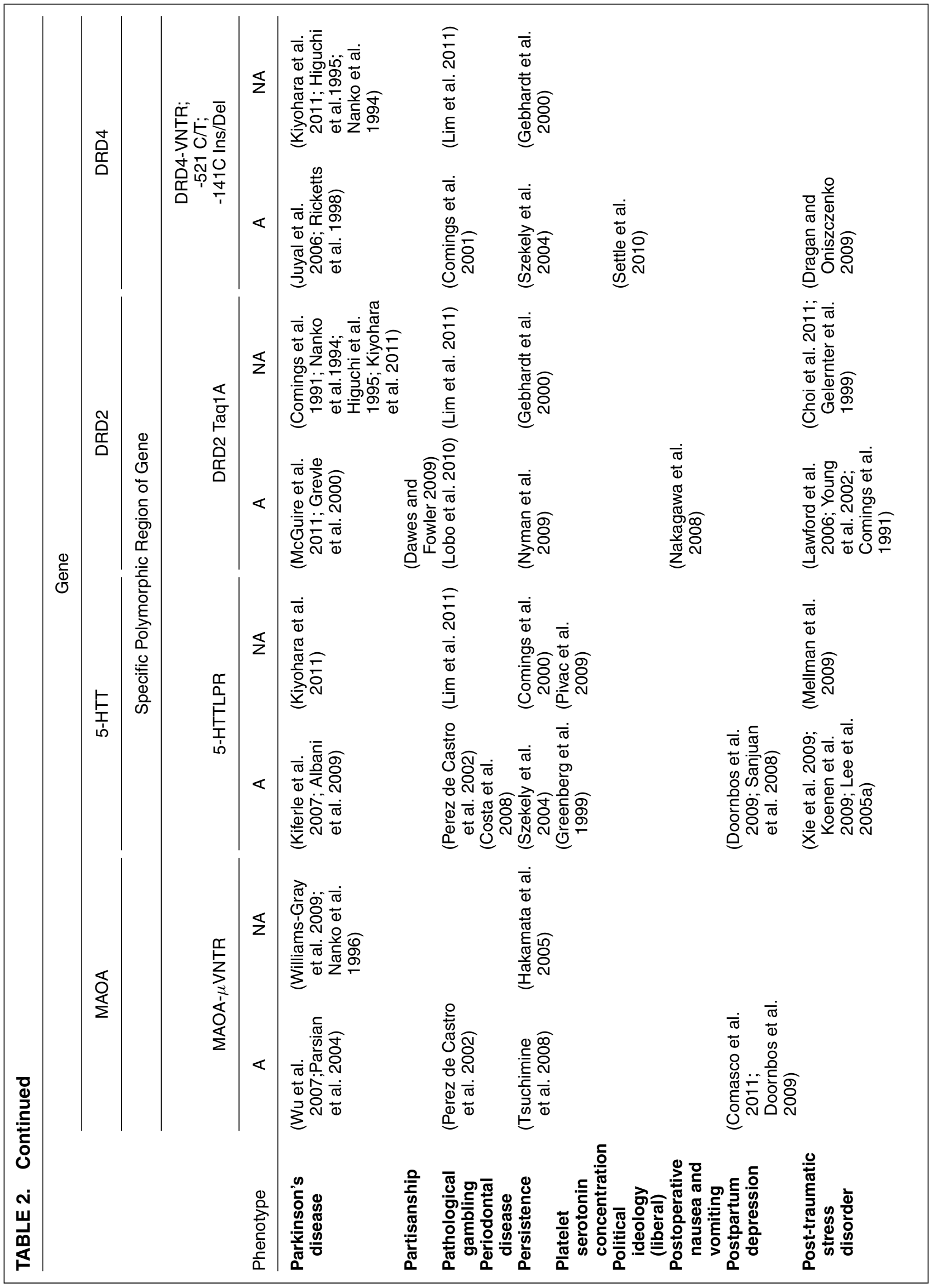




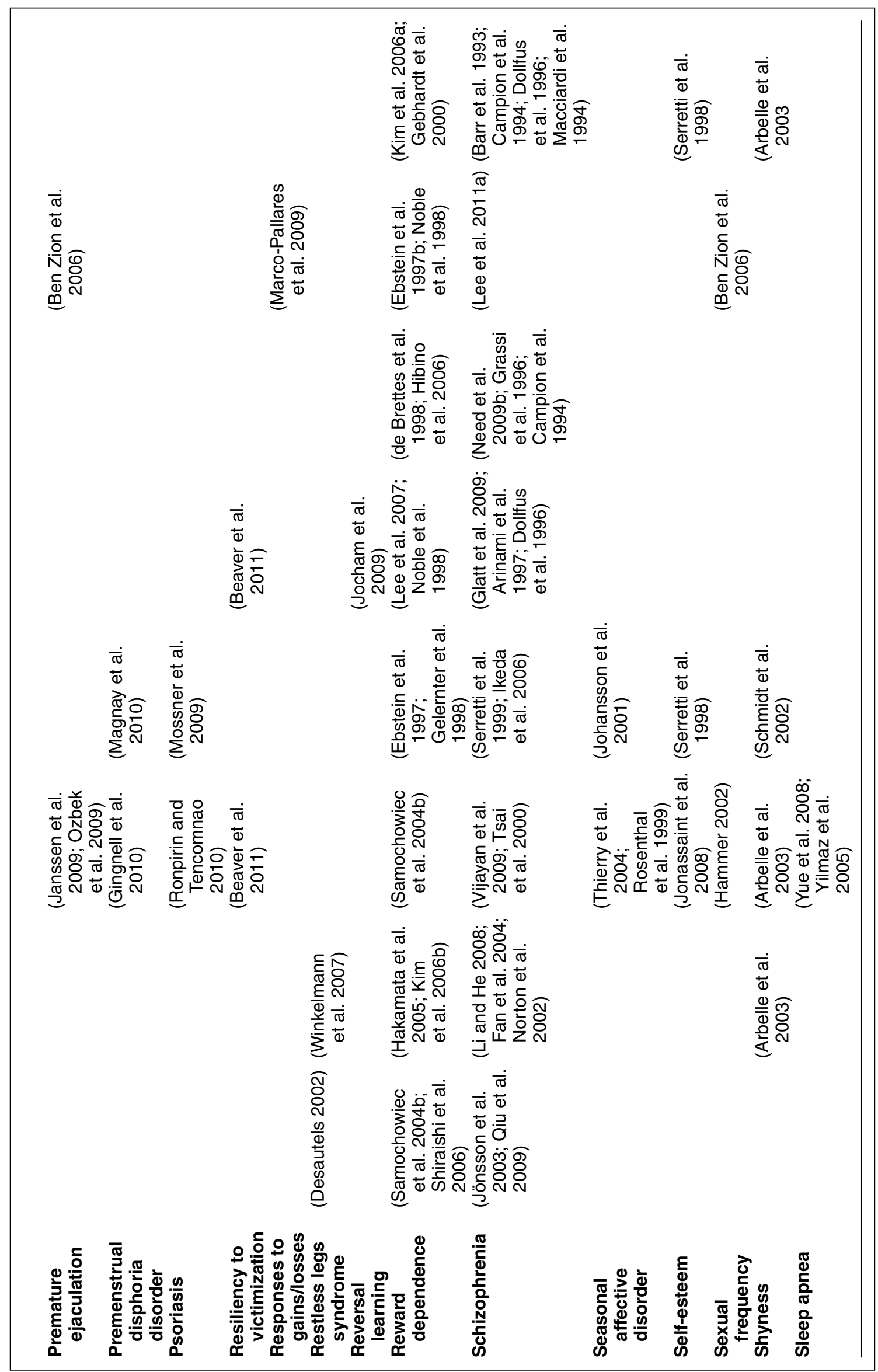




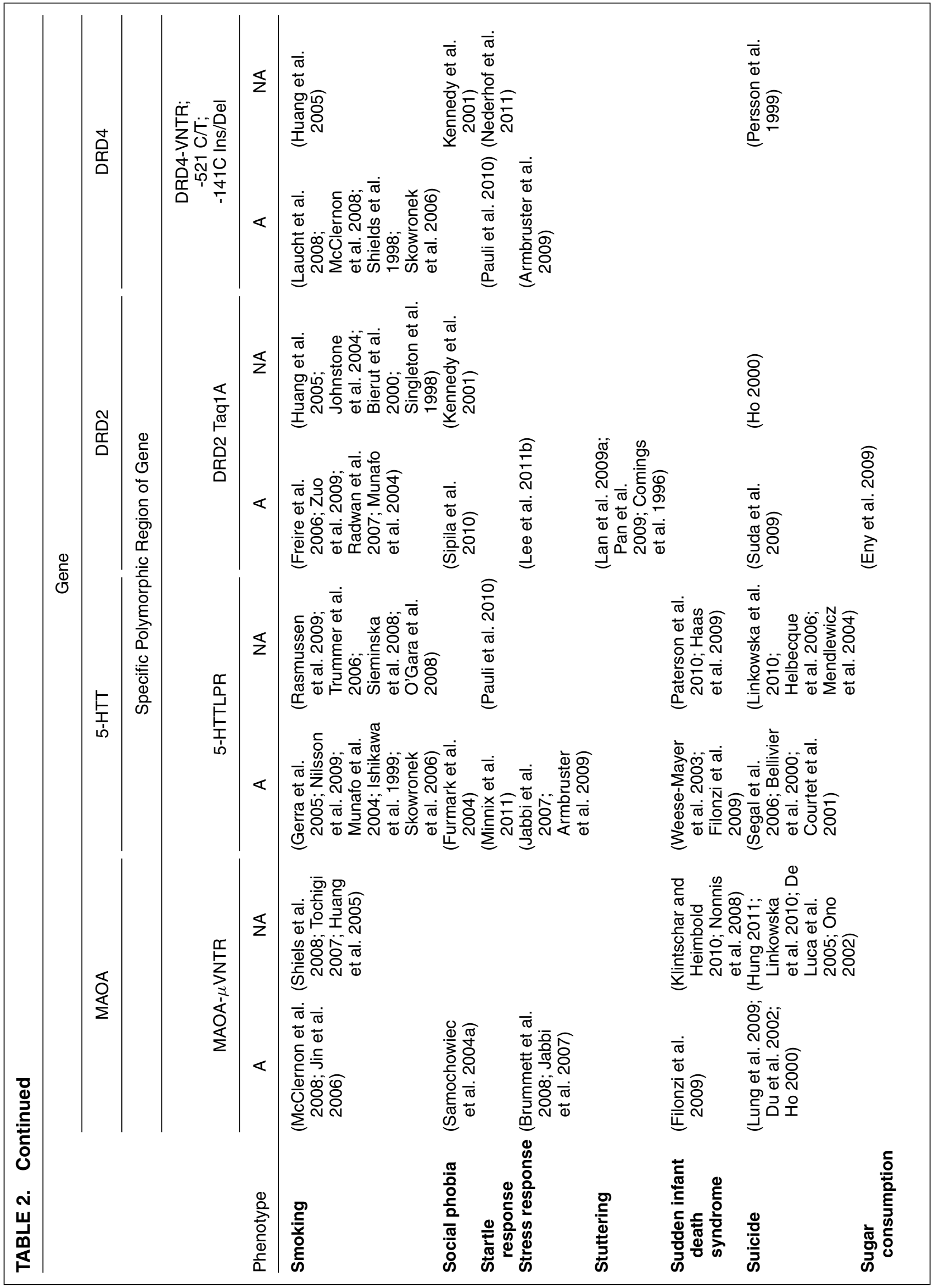




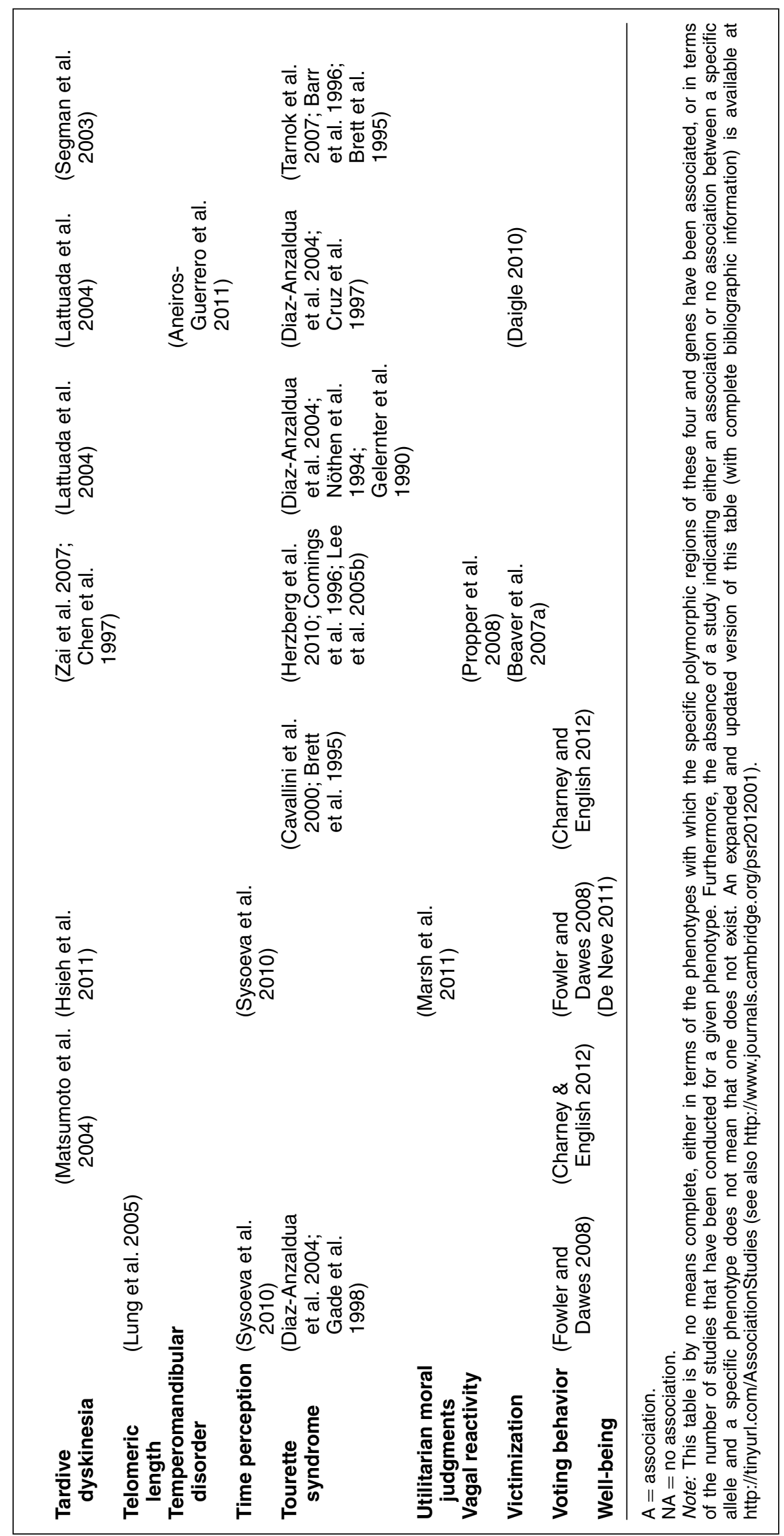


predictors of a wide range of behaviors, it is one of the few convincing ways to guard against type 1 errors.

\section{CONCLUSION}

It is a foundational assumption of candidate gene association studies in the social and behavioral sciences that one or two common polymorphisms can so greatly increase the likelihood of a complex behavior as to predict that behavior for a defined population, if not for an individual. There is an ever-growing consensus that complex traits, among which would certainly be included all politically relevant behaviors, are influenced by hundreds or thousands of proteins encoded in hundreds or thousands of genes of small effect that interact with each other, the environment, and the epigenome in complex ways. It is noteworthy that FD $(2008,590)$ do recognize this problem, if not its full implications: "It is important to emphasize that there is likely no single 'voting gene'-the results presented here suggest that at least two genes do matter and there is some (likely large) set of genes whose expression, in combination with environmental factors, influences political participation."

The problem is that a large set of genes (and if large enough, then we are simply talking about the human genome and hence the human organism), the transcriptional activity of which is influenced by the environment and each others' functional products, is incompatible with the expectation that two genes could predict voter turnout. The cogency of the search for single main-effect genes in complex human behavior must be reconsidered. Proteins encoded by at least 266 genes are involved in variation in aggression in fruit flies, yet at the same time, the heritability of aggression is less than $\sim 0.1$ because of the high level of environmental variance (even though the researchers assumed the environments were identical). If such is the level of genetic complexity and the importance of environmental interaction implicated in behavioral variation in fruit flies, why should we assume that, when it comes to human behavior, things are any simpler? We would expect all of the factors influencing political behavior to be several orders of magnitude more complex, at least on the order of the difference between the brain of the fruitfly, with $\sim 100,000$ neurons, and the human brain, with $\sim 100$ billion.

The model of the relationship between genotype and phenotype used in the social sciences makes scientific discovery in genetics appear deceptively simple: All that is required is a large data set containing relevant behavioral data and genotype data consisting of several polymorphisms (out of likely hundreds or thousands for each gene) for a handful of genes, and statistical modeling takes care of the rest. However, the validity of these statistical models depends foundationally on the validity of the genetic paradigm they presuppose. Rapid advances in biomolecular genetics indicate that this paradigm must be revised.

Genes are not predetermined by their structure to exert a specific (statistically identifiable) influence on complex phenotypes. Such a view rests on a conception of genes as "self-actualizing" entities, possessed of almost supernatural powers of phenotypic determination (Lewontin 2000). We now know that instead of being the "master molecule" that deterministically generates phenotypes, DNA is one component of a complex, integrated, interactive, and dynamic biologicalenvironmental-ecological process through which biological organisms come to manifest divergent phenotypes. One of the major theoretical conclusions to emerge from the discipline of computational and systems biology, which attempts to mathematically model biological networks, is that causation in biological systems runs in both directions: upward from the molecular level (which includes the genome and the epigenome) and downward from all other levels: cellular, tissue, organ, organism, and external environment (Noble 2010). There are feedback and feedforward loops between different levels (Tao, Zheng, and Sun 2007), and developing the mathematical and computational tools to deal with these multiple levels of causation is a major challenge.

If the traditional genocentric paradigm can be compared to the Newtonian worldview, then the emerging post-genomic view is looking more like the paradigm of relativity theory and quantum mechanics that supplanted it (Noble 2010). Beyond analogies, systems modeled on quantum mechanics are now being employed in the study of "probability landscapes of heritable epigenetic states" (on the molecular level, the epigenome acts in a highly stochastic manner):

Computational studies of biological networks can help identify components and wirings responsible for observed phenotypes. However, studying stochastic networks controlling many biological processes is challenging. Similar to Schrödinger's equation in quantum mechanics, the chemical master equation (CME) provides a basic framework for understanding stochastic networks (Cao Lu, and Liang 2010, 18445).

Given that every new advance in the science of genetics adds yet another layer of complexity (at which we have merely hinted), we have the strongest reasons to doubt that a handful of candidate genes will provide a meaningful key to understanding differences in voting behavior, political ideology, or attitudes toward abortion. Advances in genomic science suggest that this reductionist approach is ill conceived, and proponents of "genopolitics" have yet to present compelling evidence to the contrary.

\section{REFERENCES}

Alford, John R., Carolyn L. Funk, and John R. Hibbing. 2005. "Are Political Orientations Genetically Transmitted?" American Political Science Review 99 (2): 153-67.

Alia-Klein, Nelly, Aarti Kriplani, Kith Pradhan, Jim Yeming Ma, Jean Logan, Benjamin Williams, Ian W. Craig et al. 2008. "The MAO-A Genotype Does Not Modulate Resting Brain Metabolism in Adults." Psychiatry Research: Neuroimaging 164 (1): 73-76.

Alkan, Can, Bradley P. Coe, and Evan E. Eichler. 2011. "Genome Structural Variation Discovery and Genotyping." Nature Reviews Genetics 12 (5): 363-76. 
Ansolabehere, Stephen, and Eitan Hersh. 2008. "Vote Validation in the 2006 CCES." Harvard University. Unpublished manuscript.

Balciuniene, Jorune, Anne-Christine Syvänen, Howard L. McLeod, Ulf Pettersson, and Elena E. Jazin. 2001. "The Geographic Distribution of Monoamine Oxidase Haplotypes Supports a Bottleneck during the Dispersion of Modern Humans from Africa." Journal of Molecular Evolution 52 (2): 157-63.

Beaver, K. M., and J. Belsky. N.d. "Gene-Environment Interaction and the Intergenerational Transmission of Parenting: Testing the Differential-Susceptibility Hypothesis." Psychiatric Quarterly. Forthcoming.

Beaver, K. M., C. Mancini, M. DeLisi, and M.G. Vaughn. 2011. "Resiliency to Victimization: The Role of Genetic Factors." Journal of Interpersonal Violence 26 (5): 874-98

Beaver, K. M., M. Delisi, M.G. Vaughn, and J.P. Wright. 2010. "Association between the A1 Allele of the DRD2 Gene and Reduced Verbal Abilities in Adolescence and Early Adulthood." Journal of Neural Transmission 117 (7): 827-30.

Beaver, K. M., J.P. Wright, M. DeLisi, L.E. Daigle, M.L. Swatt, and C.L. Gibson. 2007a. "Evidence of a Gene $\times$ Environment Interaction in the Creation of Victimization." International Journal of Offender Therapy and Comparative Criminology 51 (6): 620-45.

Beaver, K. M., J.P. Wright, M. DeLisi, A. Walsh, M. G. Vaughn, D. Boisvert, and J. Vaske. 2007b. "A Gene $\times$ Gene Interaction between DRD2 and DRD4 Is Associated with Conduct Disorder and Antisocial Behavior in Males." Behavior and Brain Functions 3: 30 .

Bell, Edward, Julie Aitken Schermer, and Philip A. Vernon. 2009. "The Origins of Political Attitudes and Behaviours: An Analysis Using Twins." Canadian Journal of Political Science/Revue Canadienne de Science Politique 42 (4): 855-79.

Berggren, Ulf, Claudia Fahlke, Erik Aronsson, Aikaterini Karanti, Matts Eriksson, Kaj Blennow, Dag Thelle, Henrick Zetterberg, and Jan Balldin. 2006. "The Taqi DRD2 A1 Allele Is Associated with Alcohol-dependence Although Its Effect Size Is Small." Alcohol and Alcoholism 41 (5): 479-85.

Beutler, E. 2001. "Discrepancies between Genotype and Phenotype in Hematology: An Important Frontier." Blood 98 (9): 25972602.

Bickeböller, Heike, Julia N. Bailey, George J. Papanicolaou, Albert Rosenberger, and Kevin R. Viel. 2005. "Dissection of Heterogeneous Phenotypes for Quantitative Trait Mapping." Genetic Epidemiology 29 (S1): S41-47.

Bobadilla, Joseph L., Milan Macek Jr, Jason P. Fine, and Philip M. Farrell. 2002. "Cystic Fibrosis: A Worldwide Analysis of CFTR Mutations-correlation with Incidence Data and Application to Screening." Human Mutation 19 (6): 575-606.

Bogardus, Clifton. 2009. "Missing Heritability and GWAS Utility." Obesity 17 (2): 209-10.

Boklage, Charles E. 2009. "Traces of Embryogenesis Are the Same in Monozygotic and Dizygotic Twins: Not Compatible with Double Ovulation." Human Reproduction 24 (6): 1255-66.

Bourgain, Catherine, Mark Abney, Dan Schneider, Carole Ober, and Mary Sara McPeek. 2004. "Testing for Hardy-Weinberg Equilibrium in Samples with Related Individuals." Genetics 168 (4): 2349-61.

Browning, Sharon R., J. David Briley, Linda P. Briley, Gyan Chandra, Jonathan H. Charnecki, Margaret G. Ehm, Kelley A. Johansson et al. 2005. "Case-control Single-marker and Haplotypic Association Analysis of Pedigree Data." Genetic Epidemiology 28 (2): 110-22.

Bruder, C.E.G. 2008. "Phenotypically Concordant and Discordant Monozygotic Twins Display Different DNA Copy-NumberVariation Profiles." American Journal of Human Genetics 82: 1-9.

Cao, Y., H.M. Lu, and J. Liang. 2010. "Probability Landscape of Heritable and Robust Epigenetic State of Lysogeny in Phage Lambda." Proceedings of the National Academy of Science USA 107 (43): 18445-50.

Cardon, L.R., and L.J. Palmer. 2003. "Population Stratification and Spurious Allelic Association." Lancet 361: 598-604.

Carrel, Laura, and Huntington F. Willard. 2005. "X-inactivation Profile Reveals Extensive Variability in X-linked Gene Expression in Females." Nature 434 (7031): 400-04.

Caspi, A., K. Sugden, T.E. Moffitt, A. Taylor, I.W. Craig, H. Harrington, Joseph McClay et al. 2003. "Influence of Life Stress on
Depression: Moderation by a Polymorphism in the 5-HTT Gene." Science 301 (5631): 386-89.

Cassel, Carol A. 2003. "Overreporting and Electoral Participation Research." American Politics Research 31 (1): 81-92.

Cassel, Carol A. 2004. "Voting Records and Validated Voting Studies." Public Opinion Quarterly 68 (1): 102-08.

Cavalli-Sforza, L.L. 1994. The History and Geography of Human genes. Edited by P. Menozzi and A. Piazza. Princeton, N.J: Princeton University Press.

Cesarini, David, Christopher T. Dawes, James H. Fowler, Magnus Johannesson, Paul Lichtenstein, and Björn Wallace. 2008. "Heritability of Cooperative Behavior in the Trust Game." Proceedings of the National Academy of Sciences 105 (10): 3721-26.

Chanock, Stephen J., Teri Manolio, Michael Boehnke, Eric Boerwinkle, David J. Hunter, Gilles Thomas, Joel N. Hirschhorn et al. 2007. "Replicating Genotype-Phenotype Associations." $N a$ ture 447 (7145): 655-60.

Childs, E., C. Hohoff, J. Deckert, K. Xu, J. Badner, and H. de Wit. 2008. "Association between ADORA2A and DRD2 Polymorphisms and Caffeine-induced Anxiety." Neuropsychopharmacology 33 (12): 2791-2800.

Chipman, P., A.F. Jorm, M. Prior, A. Sanson, D. Smart, X. Tan, and S. Easteal. 2007. "No Interaction between the Serotonin Transporter Polymorphism (5-HTTLPR) and Childhood Adversity or Recent Stressful Life Events on Symptoms of Depression: Results from Two Community Surveys." American Journal of Medical Genetics Part B: Neuropsychiatric Genetics 144B (4): 561-65.

Cirulli, Elizabeth T., and David B. Goldstein. 2007. "In Vitro Assays Fail to Predict In Vivo Effects of Regulatory Polymorphisms." Human Molecular Genetics 16 (16): 1931-39.

Clay Montier, Laura L., Janice J. Deng, and Yidong Bai. 2009. "Number Matters: Control of Mammalian Mitochondrial DNA Copy Number." Journal of Genetics and Genomics 36 (3): 125-31.

Comings, D.E. 1998. "Why Different Rules Are Required for Polygenic Inheritance: Lessons from Studies of the DRD2 Gene." Alcohol 16 (1): 61-70.

Comings, D.E., D. Muhleman, and R. Gysin. 1996. "Dopamine D2 Receptor (DRD2) Gene and Susceptibility to Posttraumatic Stress Disorder: A Study and Replication." Biological Psychiatry 40 (5): 368-72.

Conrad, Donald F., Dalila Pinto, Richard Redon, Lars Feuk, Omer Gokcumen, Yujun Zhang, Jan Aerts et al. 2010. "Origins and Functional Impact of Copy Number Variation in the Human Genome." Nature 464 (7289): 704-12.

Cotton, R.G.H., and O. Horaitis. 2002. "The HUGO Mutation Database Initiative.” Pharmacogenomics Journal 2 (1): 16-19.

Coufal, Nicole G., Jose L. Garcia-Perez, Grace E. Peng, Gene W. Yeo, Yangling Mu, Michael T. Lovci, Maria Morrell, Sue O’Shea, John V. Moran, and Fred H. Gage. 2009. "L1 Retrotransposition in Human Neural Progenitor Cells." Nature 460 (7259): 1127-31.

Daw, J., and G. Guo. 2011. "The Influence of Three Genes on Whether Adolescents Use Contraception, USA 1994-2002.” Population Studies 65 (3): 253-71.

Dawes, Christopher T., and James H. Fowler. 2009. "Partisanship, Voting, and the Dopamine D2 Receptor Gene." Journal of Politics 71 (3): 1157-71.

Dawkins, Richard. 2006. The Selfish Gene. New York: Oxford University Press.

Dear, Paul H. 2009. "Copy-number Variation: The End of the Human Genome?" Trends in Biotechnology 27 (8): 448-54.

De Neve, Jan-Emmanuel, and James H. Fowler. 2010. "The MAOA Gene Predicts Credit Card Debt." Social Science Research Network. http://papers.ssrn.com/sol3/papers.cfm? abstract_id=1457224 (accessed November 10, 2011).

Deckert, J., M. Catalano, Y.V. Syagailo, M. Bosi, O. Okladnova, D. DiBella, M.M. Nöthen et al. 1999. "Excess of High Activity Monoamine Oxidase A Gene Promoter Alleles in Female Patients with Panic Disorder." Human Molecular Genetics 8 (4): 62124.

DeLisi, Matt, Kevin M. Beaver, Michael G. Vaughn, and John Paul Wright. 2009. "All in the Family." Criminal Justice and Behavior 36 (11): 1187-97.

Dick, D.M., B. Riley, and K.S. Kendler. 2010. "Nature and Nurture in Neuropsychiatric Genetics: Where Do We Stand?" Dialogues in Clinical Neuroscience 12 (1): 7-23. 
Dipple, Katrina M., James K. Phelan, and Edward R.B. McCabe. 2001. "Consequences of Complexity within Biological Networks: Robustness and Health, or Vulnerability and Disease." Molecular Genetics and Metabolism 74 (1/2): 45-50.

Doll, B.B., K.E. Hutchison, and M.J. Frank. 2011. "Dopaminergic Genes Predict Individual Differences in Susceptibility to Confirmation Bias." Journal of Neuroscience 31 (16): 6188-98.

Eaves, Lindon, and Peter Hatemi. 2008. "Transmission of Attitudes toward Abortion and Gay Rights: Effects of Genes, Social Learning, and Mate Selection." Behavior Genetics 38 (3): 247-56.

Edwards, Alexis, Stephanie M. Rollmann, Theodore J. Morgan, and Trudy F.C. Mackay. 2006. "Quantitative Genomics of Aggressive Behavior in Drosophila Melanogaster." PLoS Genetics 2 (9): e154.

Edwards, Alexis, Julien Ayroles, Eric Stone, Mary Carbone, Richard Lyman, and Trudy Mackay. 2009a. "A Transcriptional Network Associated with Natural Variation in Drosophila Aggressive Behavior." Genome Biology 10 (7): R76: 1-11.

Edwards, Alexis, Liesbeth Zwarts, Akihiko Yamamoto, Patrick Callaerts, and Trudy Mackay. 2009b. "Mutations in Many Genes Affect Aggressive Behavior in Drosophila Melanogaster." BMC Biology 7 (1): 29.

Emanuele, E., N. Brondino, S. Pesent, S. Re, and D. Geroldi. 2007. "Genetic Loading on Human Loving Styles." Neuroendocrinology Letters 28 (6): 815-21.

Esau, Luke, Mandeep Kaur, Lucinda Adonis, and Zainunisha Arieff. 2008. "The 5-HTTLPR Polymorphism in South African Healthy Populations: A Global Comparison." Journal of Neural Transmission 115 (5): 755-60.

File, Thom, and Sarah Crissey. 2010. "Voting and Registration in the Election of November 2008: Population Characteristics." Washington, DC: U.S. Census Bureau. www.census.gov/ prod/2010pubs/p20-562.pdf (Accessed November 10, 2011).

Flint, J., and M.R. Munafo. 2007. "The Endophenotype Concept in Psychiatric Genetics.” Psychological Medicine 37: 163-80.

Fowler, James H., Laura A. Baker, and Christopher T. Dawes. 2008. "Genetic Variation in Political Participation." American Political Science Review 102 (2): 233-48.

Fowler, James H., and Christopher T. Dawes. 2008. "Two Genes Predict Voter Turnout." Journal of Politics 70 (3): 579-94.

Fowler, James H., J.E. Settle, and N.A. Christakis. 2011. "Correlated Genotypes in Friendship Networks." Proceedings of the National Academy of Sciences USA 108 (5): 1993-97.

Fowler, Joanna S., Nelly Alia-Klein, Aarti Kriplani, Jean Logan, Benjamin Williams, Wei Zhu, Ian W. Craig et al. 2007. "Evidence That Brain MAO A Activity Does Not Correspond to MAO A Genotype in Healthy Male Subjects." Biological Psychiatry 62 (4): 355-58.

Fraga, M.F., E. Ballesta, M.F. Paz, S. Ropero, and F. Setien. 2005. "Epigenetic Differences Arise during the Lifetime of Monozygotic Twins." Proceedings of the National Academy of Sciences USA 102: 10604-09.

Franke, Barbara, Benjamin Neale, and Stephen Faraone. 2009. "Genome-wide Association Studies in ADHD." Human Genetics 126 (1): $13-50$

Frazzetto, Giovanni, Giorgio Di Lorenzo, Valeria Carola, Luca Proietti, Ewa Sokolowska, Alberto Siracusano, Cornelius Gross, and Alfonso Troisi. 2007. "Early Trauma and Increased Risk for Physical Aggression during Adulthood: The Moderating Role of MAOA Genotype." PLoS ONE 2 (5): e486.

Gottesman, I., and J. Shields. 1973. "Genetic Theorizing and Schizophrenia." British Journal of Psychiatry 122 (566): 15-30.

Gressler, Sabine, and Alexander G. Haslberger, eds. 2010. Epigenetics and Human Health: Linking Hereditary, Environmental, and Nutritional Aspects. Weinheim, Germany: Wiley-VCH.

Grevle, L., C. Guzey, H. Hadidi, R. Brennersted, J.R. Idle, and J. Aasly. 2000. "Allelic Association between the DRD2 TaqI A Polymorphism and Parkinson's Disease." Movement Disorders 15 (6): 1070-74.

Guo, G., and K.H. Tillman. 2009. "Trajectories of Depressive Symptoms, Dopamine D2 and D4 Receptors, Family Socioeconomic Status and Social Support in Adolescence and Young Adulthood." Psychiatric Genetics 19 (1): 14-26.

Guo, G., M.E. Roettger, and J.C. Shih. 2007a. "Contributions of the DAT1 and DRD2 Genes to Serious and Violent Delinquency among Adolescents and Young Adults." Human Genetics 121 (1): 125-36.

Guo, Guang, Kirk Wilhelmsen, and Nathan Hamilton. 2007b. "Gene-lifecourse Interaction for Alcohol Consumption in Adolescence and Young Adulthood: Five Monoamine Genes." American Journal of Medical Genetics Part B: Neuropsychiatric Genetics 144B (4): 417-23.

Guo, G., and Y. Tong. 2006. "Age at First Sexual Intercourse, Genes, and Social Context: Evidence from Twins and the Dopamine D4 Receptor Gene." Demography 43 (4): 747-69.

Halpern, Carolyn, Christine Kaestle, Guang Guo, and Denise Hallfors. 2007. "Gene-environment Contributions to Young Adult Sexual Partnering." Archives of Sexual Behavior 36 (4): 543-54.

Haque, F. Nipa, Irving I. Gottesman, and Albert H.C. Wong. 2009. "Not Really Identical: Epigenetic Differences in Monozygotic Twins and Implications for Twin Studies in Psychiatry." American Journal of Medical Genetics Part C: Seminars in Medical Genetics $151 \mathrm{C}(2)$ : $136-41$.

Hatemi, Peter K., John R. Alford, John R. Hibbing, Nicholas G. Martin, and Lindon J. Eaves. 2009. "Is There a 'Party' in Your Genes?" Political Research Quarterly 62 (3): 584-600.

Hatemi, Peter K., Sarah Medland, Katherine Morley, Andrew Heath, and Nicholas Martin. 2007. "The Genetics of Voting: An Australian Twin Study." Behavior Genetics 37 (3): 435-48.

Heils, A., A. Teufel, S. Petri, G. Stober, P. Riederer, D. Bengel, and K.P. Lesch. 1996. "Allelic Variation of Human Serotonin Transporter Gene Expression." Journal of Neurochemistry 66: 262124.

Huizinga, David, Brett C. Haberstick, Andrew Smolen, Scott Menard, Susan E. Young, Robin P. Corley, Michael C. Stallings, Jennifer Grotpeter, and John K. Hewitt. 2006. "Childhood Maltreatment, Subsequent Antisocial Behavior, and the Role of Monoamine Oxidase A Genotype.” Biological Psychiatry 60 (7): 677-83.

Hunley, Keith L., Meghan E. Healy, and Jeffrey C. Long. 2009. "The Global Pattern of Gene Identity Variation Reveals a History of Long-range Migrations, Bottlenecks, and Local Mate Exchange: Implications for Biological Race." American Journal of Physical Anthropology 139 (1): 35-46.

Jacob, Christian P., Johannes Muller, Michael Schmidt, Katrin Hohenberger, Lise Gutknecht, Andreas Reif, Armin Schmidtke, Rainard Mössner, and Klaus Peter Lesch. 2005. "Cluster B Personality Disorders Are Associated with Allelic Variation of Monoamine Oxidase A Activity." Neuropsychopharmacology 30 (9): 1711-18.

Jensen, O.N. 2004. "Modification-specific Proteomics: Characterization of Post-translational Modifications by Mass Spectrometry." Current Opinions in Chemical Biology 8 (1): 33-41.

Jirtle, Randy L., and Michael K. Skinner. 2007. "Environmental Epigenomics and Disease Susceptibility." Nature Reviews Genetics 8 (4): $253-62$.

Jonassaint, C.R, A. Ashely-Koch, K. Whitfield, and R.B. Williams. 2008. "The Serotonin Transporter Gene Moderates Environmental Stress Effects on Self-esteem." Presented at the American Psychosomatic Society. Baltimore. http://www. cpc.unc.edu/projects/addhealth/pubs/61863 (accessed November 10, 2011).

Kim-Cohen, J., A. Caspi, A. Taylor, B. Williams, R. Newcombe, I.W. Craig, and T.E. Moffitt. 2006. "MAOA, Maltreatment, and Geneenvironment Interaction Predicting Children's Mental Health: New Evidence and a Meta-analysis." Molecular Psychiatry 11 (10): 903-13.

Klein, T.A., J. Neumann, M. Reuter, J. Hennig, D.Y. von Cramon, and M. Ullsperger. 2007. "Genetically Determined Differences in Learning from Errors." Science 318 (5856): 1642-45.

Kraft, P. 2008. "Curses-Winner's and Otherwise-in Genetic Epidemiology." Epidemiology 19: 649-51.

Lango Allen, Hana, Karol Estrada, Guillaume Lettre, Sonja I. Berndt, Michael N. Weedon, Fernando Rivadeneira, Cristen J. Willer et al. 2010. "Hundreds of Variants Clustered in Genomic Loci and Biological Pathways Affect Human Height." Nature 467 (7317): 832-38.

Larsen, Klaus, Jørgen Holm Petersen, Esben Budtz-Jørgensen, and Lars Endahl. 2000. "Interpreting Parameters in the Logistic Regression Model with Random Effects.” Biometrics 56 (3): 909-14. 
Lesch, Klaus-Peter, Dietmar Bengel, Armin Heils, Sue Z. Sabol, Benjamin D. Greenberg, Susanne Petri, J. Benjamin, C.R. Müller, D.H. Hamer, Dennis L. Murphy. 1996. "Association of Anxietyrelated Traits with a Polymorphism in the Serotonin Transporter Gene Regulatory Region.” Science 274 (5292): 1527-31.

Lee, C.C., I.C. Chou, C.H. Tsai, T.R. Wang, T.C. Li, and F.J. Tsai. 2005. "Dopamine Receptor D2 Gene Polymorphisms Are Associated in Taiwanese Children with Tourette Syndrome." Pediatric Neurology 33 (4): 272-76.

Lewontin, Richard C. 2000. The Triple Helix: Gene, Organism, and Environment. Cambridge, MA: Harvard University Press.

Lopez-Rodriguez, R., M. Roman, J. Novalbos, M.L. Pelegrina, D. Ochoa, and F. Abad-Santos. 2011. "DRD2 Taq1A Polymorphism Modulates Prolactin Secretion Induced by Atypical Antipsychotics in Healthy Volunteers." Journal of Clinical Psychopharmacology 31 (5): 555-62.

Lotrich, Francis E., Bruce G. Pollock, and Robert E. Ferrell. 2003. "Serotonin Transporter Promoter Polymorphism in African Americans: Allele Frequencies and Implications for Treatment." American Journal of PharmacoGenomics 3 (2): 145-47.

Machin, Geoffrey. 2009. "Non-identical Monozygotic Twins, Intermediate Twin Types, Zygosity Testing, and the Non-random Nature of Monozygotic Twinning: A Review." American Journal of Medical Genetics Part C: Seminars in Medical Genetics $151 \mathrm{C}$ (2): 110-27.

Manolio, Teri A., Francis S. Collins, Nancy J. Cox, David B. Goldstein, Lucia A. Hindorff, David J. Hunter, Mark I. McCarthy et al. 2009. "Finding the Missing Heritability of Complex Diseases." Nature 461 (7265): 747-53.

Marchetto, Maria C.N., Fred H. Gage, and Alysson R. Muotri. 2010. "Retrotransposition and Neuronal Diversity." In Perspectives of Stem Cells: From Tools for Studying Mechanisms of Neuronal Differentiation towards Therapy, ed. H. Ulrich. Dordrecht, the Netherlands: Springer, 87-96.

Marchini, J., L.R. Cardon, M.S. Phillips, and P. Donnelly. 2004. "The Effects of Human Population Structure on Large Genetic Association Studies." Nature Genetics 36: 512-17.

Martin, Sandra L. 2009. "Developmental Biology: Jumping-gene Roulette." Nature 460 (7259): 1087-88.

McCabe, Linda L., and Edward R.B. McCabe. 2006. "Complexity in Genetic Diseases: How Patients Inform the Science by Ignoring the Dogma." American Journal of Medical Genetics Part A 140A (2): 160-61.

McClellan, Jon, and Mary-Claire King. 2010. "Genetic Heterogeneity in Human Disease." Cell 141 (2): 210-17.

McClernon, F. Joseph, Bernard F. Fuemmeler, Scott H. Kollins, Melanie E. Kail, and Allison E. Ashley-Koch. 2008. "Interactions between Genotype and Retrospective ADHD Symptoms Predict Lifetime Smoking Risk in a Sample of Young Adults." Nicotine and Tobacco Research 10 (1): 117-27.

McCrae, Robert R., Matthew Scally, Antonio Terracciano, Gonçalo R. Abecasis, and Paul T. Costa Jr. 2010. "An Alternative to the Search for Single Polymorphisms: Toward Molecular Personality Scales for the Five-factor Model." Journal of Personality and Social Psychology 99 (6): 1014-24.

McDermott, Rose, Dustin Tingley, Jonathan Cowden, Giovanni Frazzetto, and Dominic D.P. Johnson. 2009. "Monoamine Oxidase A Gene (MAOA) Predicts Behavioral Aggression Following Provocation." Proceedings of the National Academy of Sciences USA 106 (7): 2118-23.

McIntosh, Hugh, Daniel Hart, and James Youniss. 2007. "The Influence of Family Political Discussion on Youth Civic Development: Which Parent Qualities Matter?" PS: Political Science and Politics 40 (3): 495-99.

Mehler, Mark F. 2008. "Epigenetics and the Nervous System." Annals of Neurology 64 (6): 602-17.

Mertins, V., A.B. Schote, W. Hoffeld, M. Griessmair, and J. Meyer. 2011. "Genetic Susceptibility for Individual Cooperation Preferences: The Role of Monoamine Oxidase A Gene (MAOA) in the Voluntary Provision of Public Goods." PLoS ONE 6 (6): 16.

Middeldorp, Christel, Eco de Geus, A. Beem, Nico Lakenberg, Jouke-Jan Hottenga, P. Slagboom, and Dorret Boomsma. 2007. "Family Based Association Analyses between the Serotonin Transporter Gene Polymorphism (5-HTTLPR) and Neuroticism, Anxiety and Depression.” Behavior Genetics 37 (2): 294-301.
Migeon, Barbara R. 2007. Females Are Mosaics: X Inactivation and Sex Differences in Disease. Oxford: Oxford University Press.

Morton, Newton E. 2005. "Linkage Disequilibrium Maps and Association Mapping." Journal of Clinical Investigation 115 (6): 142530.

Nagel, R.L. 2005. "Epistasis and the Genetics of Human Diseases." Comptes Rendus Biologies 328 (7): 606-15.

Naylor, L., B. Dean, A. Pereira, A. Mackinnon, A. Kouzmenko, and D. Copolov. 1998. "No Association between the Serotonin Transporter-linked Promoter Region Polymorphism and Either Schizophrenia or Density of the Serotonin Transporter in Human Hippocampus." Molecular Medicine 4 (10): 671-74.

Need, A.C., and D.B. Goldstein. 2010. "Whole Genome Association Studies in Complex diseases: where do we stand?" Dialogues in Clinical Neuroscience 12 (1): 37-46.

Neuhaus, J.M., W.W. Hauck, and J.D. Kalbfleisch. 1992. "The Effects of Mixture Distribution Misspecification When Fitting Mixedeffects Logistic Models." Biometrika 79 (4): 755-62.

Newman, Dina L., Mark Abney, Mary Sara McPeek, Carole Ober, and Nancy J. Cox. 2001. "The Importance of Genealogy in Determining Genetic Associations with Complex Traits." American Journal of Human Genetics 69 (5): 1146-48.

Nilsen, T.W., and B.R. Graveley. 2010." Expansion of the Eukaryotic Proteome by Alternative Splicing." Nature 463 (7280): 457-63.

Nisoli, E., A. Brunani, E. Borgomainerio, C. Tonello, L. Dioni, L. Briscini, G. Redaelli, E. Molinari, F. Cavagnini, and M.O. Carruba. 2007. "D2 Dopamine Receptor (DRD2) Gene Taq1A Polymorphism and the Eating-related Psychological Traits in Eating Disorders (Anorexia Nervosa and Bulimia) and Obesity." Eating and Weight Disorders 12 (2): 91-96.

Noble, Denis. 2010. "Biophysics and Systems Biology." Philosophical Transactions of the Royal Society A: Mathematical, Physical and Engineering Sciences 368 (1914): 1125-39.

Nordquist, Niklas, and Lars Oreland. 2010. "Serotonin, Genetic Variability, Behaviour, and Psychiatric Disorders: A Review." Upsala Journal of Medical Sciences 115 (1): 2-10.

Notini, A.J., J.M. Craig, and S.J. White. 2008. "Copy Number Variation and Mosaicism." Cytogenetic and Genome Research 123 (1-4): $270-77$.

Nyman, Emma S., Anu Loukola, Teppo Varilo, Jesper Ekelund, Juha Veijola, Matti Joukamaa, Anja Taanila et al. 2009. "Impact of the Dopamine Receptor Gene Family on Temperament Traits in a Population-based Birth Cohort." American Journal of Medical Genetics Part B: Neuropsychiatric Genetics 150B (6): 85465

Ollikainen, Miina, Katherine R. Smith, Eric Ji-Hoon Joo, Hong Kiat $\mathrm{Ng}$, Roberta Andronikos, Boris Novakovic, Nur Khairunnisa Abdul Aziz et al. 2010. "DNA Methylation Analysis of Multiple Tissues from Newborn Twins Reveals Both Genetic and Intrauterine Components to Variation in the Human Neonatal Epigenome." Human Molecular Genetics 19 (21): 4176-88.

Ooi, Lezanne, and Ian C. Wood. 2008. "Regulation of Gene Expression in the Nervous System." Biochemical Journal 414: 327-41.

Paclt, I., I. Drtilkova, M. Kopeckova, P. Theiner, O. Sery, and N. Cermakova. 2010. "The Association between TaqI A Polymorphism of ANKK1 (DRD2) Gene and ADHD in Czech Boys Aged between 6 and 13 Years." Neuroendocrinology Letters 31 (1): 131-36.

Pai, Chung-Yen, Su-Lien Chou, and Frank Fu-Yuan Huang. 2007. "Assessment of the Role of a Functional VNTR Polymorphism in MAOA Gene Promoter: A Preliminary Study." Forensic Science Journal 6 (2): 37-43.

Peltonen, Leena, and Victor A. McKusick. 2001. "Dissecting Human Disease in the Postgenomic Era." Science 291 (5507): 1224-29.

Pergament, E. 2005. "Postnatal Zygosity Determination." In Multiple Pregnancy: Epidemiology, Gestation, and Perinatal Outcome, eds. I. Blickstein and L.G. Keith. London: Parthenon, 393-402.

Petronis, Arturas. 2010. "Epigenetics as a Unifying Principle in the Aetiology of Complex Traits and Diseases." Nature 465 (7299): 721-27.

Plomin, Robert. 1990. "The Role of Inheritance in Behavior." Science 248 (4952): 183-88

Plomin, Robert, and Oliver S.P. Davis. 2009. "The Future of Genetics in Psychology and Psychiatry: Microarrays, Genome-wide Association, and Non-coding RNA." Journal of Child Psychology and Psychiatry 50 (1/2): 63-71. 
Plutzer, Eric. 2002. "Becoming a Habitual Voter: Inertia, Resources, and Growth in Young Adulthood." American Political Science Review 96 (1): 41-56.

Power, Tom, Robert Stewart, Marie-Laure Ancelin, Isabelle Jaussent, Alain Malafosse, and Karen Ritchie. 2010. "5-HTTLPR Genotype, Stressful Life Events, and Late-life Depression: No Evidence of Interaction in a French Population." Neurobiology of Aging 31 (5): 886-87.

Prichard, Z., A. Mackinnon, A.F. Jorm, and S. Easteal. 2008. "No Evidence for Interaction between MAOA and Childhood Adversity for Antisocial Behavior." American Journal of Medical Genetics Part B-Neuropsychiatric Genetics 147B (2): 228-32.

Redon, Richard, Shumpei Ishikawa, Karen R. Fitch, Lars Feuk, George H. Perry, T. Daniel Andrews, Heike Fiegler et al. 2006. "Global Variation in Copy Number in the Human Genome." Nature 444 (7118): 444-54.

Risch, N., R. Herrell, T. Lehner, K.Y. Liang, L. Eaves, J. Hoh, A. Griem, M. Kovacs, J. Ott, and K.R. Merikangas. 2009. "Interaction between the Serotonin Transporter Gene (5-HTTLPR), Stressful Life Events, and Risk of Depression A Meta-analysis." Journal of the American Medical Association 301 (23): 2462-71.

Sabol, S.Z., S. Hu, and D. Hamer. 1998. "A Functional Polymorphism in the Monoamine Oxidase A Gene Promoter." Human Genetics 103 (3): 273-79.

Schnable, P.S., D. Ware, R.S. Fulton, J.C. Stein, F. Wei, S. Pasternak, Chengzhi Liang et al. 2009. "The B73 Maize Genome: Complexity, Diversity, and Dynamics." Science 326 (5956): 1112-15.

Science Daily. 2008. Political Participation Is Partially Rooted in Genetic Inheritance. July 3. http://www.sciencedaily.com/releases/ 2008/07/080701083517.htm (accessed November 10, 2011).

Settle, Jaime E., Christopher T. Dawes, Nicholas A. Christakis, and James H. Fowler. 2010. "Friendships Moderate an Association between a Dopamine Gene Variant and Political Ideology." Journal of Politics 72 (4): 1189-98.

Sgaramella, Vittorio, and Paola A. Astolfi. 2010. "Somatic Genome Variations Interact with Environment, Genome and Epigenome in the Determination of the Phenotype: A Paradigm Shift in Genomics?" DNA Repair 9 (4): 470-73.

Shahmoradgoli Najafabadi, M., M. Ohadi, M.T. Joghataie, F. Valaie, Y. Riazalhosseini, H. Mostafavi, Fariba Mohammadbeigi, and H. Najmabadi. 2005. "Association between the DRD2 A1 Allele and Opium Addiction in the Iranian Population." American Journal of Medical Genetics Part B-Neuropsychiatric Genetics 5 (1): 39-41.

Shanahan, M.J., L.D. Erickson, S. Vaisey, and A. Smolen. 2007. "Helping Relationships and Genetic Propensities: A Combinatoric Study of DRD2, Mentoring, and Educational Continuation." Twin Research in Human Genetics 10 (2): 285-98.

Shanahan, M.J., S. Vaisey, L.D. Erickson, and A. Smolen. 2008. "Environmental Contingencies and Genetic Propensities: Social Capital, Educational Continuation, and Dopamine Receptor Gene DRD2." American Journal of Semiotics 114 (86): S260-86.

Shioe, K., T. Ichimiya, T. Suhara, A. Takano, Y. Sudo, F. Yasuno, Masami Hirano et al. 2003. "No Association between Genotype of the Promoter Region of Serotonin Transporter Gene and Serotonin Transporter Binding in Human Brain Measured by PET." Synapse 48 (4): 184-88.

Skipper, Magdalena. 2008. "Human Genetics: Not-so-identical Twins." Nature Reviews Genetics 9: 250-51.

Slatkin, Montgomery. 2009. "Epigenetic Inheritance and the Missing Heritability Problem." Genetics 182 (3): 845-50.

Squassina, A., M. Manchia, M. Costa, C. Chillotti, R. Ardau, M. Del Zompo, and G. Severino. 2011. "Age at Onset in Bipolar Disorder Investigation of the Role of TaqIA Polymorphism of DRD2 Gene in a Sardinian Sample." European Psychiatry 26 (3): 141-43.

Stephens, J. Claiborne, Julie A. Schneider, Debra A. Tanguay, Julie Choi, Tara Acharya, Scott E. Stanley, Ruhong Jiang et al. 2001. "Haplotype Variation and Linkage Disequilibrium in 313 Human Genes." Science 293 (5529): 489-93.

Stöber, Gerald, Yana V. Syagailo, Olga Okladnova, Gerd Jungkunz, Michael Knapp, Helmut Beckmann, and Klaus-Peter Lesch. 1999. "Functional PAX-6 Gene-linked Polymorphic Region: Potential Association with Paranoid Schizophrenia." Biological Psychiatry 45 (12): 1585-91.
Suda, A., C. Kawanishi, I. Kishida, R. Sato, T. Yamada, M. Nakagawa, H. Hasegawa, D. Kato, T. Furuno, and Y. Hirayasu. 2009. "Dopamine D2 Receptor Gene Polymorphisms Are Associated with Suicide Attempt in the Japanese Population." Neuropsychobiology 59 (2): 130-34.

Talmud, Philippa J., Aroon D. Hingorani, Jackie A. Cooper, Michael G. Marmot, Eric J. Brunner, Meena Kumari, Mika Kivimäki, and Steve E Humphries. 2010. "Utility of Genetic and Nongenetic Risk Factors in Prediction of Type 2 Diabetes: Whitehall II Prospective Cohort Study." British Medical Journal 340.

Tao, Y., X. Zheng, and Y. Sun. 2007. "Effect of Feedback Regulation on Stochastic Gene Expression." Journal of Theoretical Biology 247: 827-36.

Turkheimer, Eric. 2000. "Three Laws of Behavior Genetics and What They Mean." Current Directions in Psychological Science 9 (5): 160-64.

Vaske, Jamie, Matthew Makarios, Danielle Boisvert, Kevin M. Beaver, and John Paul Wright. 2009a. "The Interaction of DRD2 and Violent Victimization on Depression: An Analysis by Gender and Race." Journal of Affective Disorders 112 (1): 120-25.

Vaske, Jamie, J. Newsome, M. Makarios, J. P. Wright, B. B. Boutwell, and K. M. Beaver. 2009b. "Interaction of 5HTTLPR and Marijuana Use on Property Offending." Biodemography and Social Biology 55 (1): 93-102.

Vaughn, Michael G., Kevin M. Beaver, Matt DeLisi, Brian E. Perron, and Lisa Schelbe. 2009. "Gene-environment Interplay and the Importance of Self-control in Predicting Polydrug Use and Substance-related Problems." Addictive Behaviors 34 (1): 11216.

Wachtel, Stephen S. 1994. Molecular Genetics of Sex Determination. San Diego, CA: Academic Press.

Walter, N.T., S.A. Markett, C. Montag, and M. Reuter. 2011. “A Genetic Contribution to Cooperation: Dopamine-relevant Genes Are Associated with Social Facilitation." Social Neuroscience 6 (3): 289-301.

Walters, Ryan D., Jennifer F. Kugel, and James A. Goodrich. 2009. "Invaluable Junk: The Cellular Impact and Function of Alu and B2 RNAs." IUBMB Life 61 (8): 831-37.

Weatherall, David J. 2000. "Science, Medicine, and the Future: Single Gene Disorders or Complex Traits: Lessons from the Thalassaemias and Other Monogenic Diseases." British Medical Journal 321 (7269): 1117-20.

Whitelaw, N.C., and E. Whitelaw. 2006. "How Lifetimes Shape Epigenotype within and across Generations." Human Molecular Genetics 15: R131-37.

Willeit, M., J. Stastny, W. Pirker, N. Praschak-Rieder, A. Neumeister, S. Asenbaum, J. Tauser et al. 2001. "No Evidence for In Vivo Regulation of Midbrain Serotonin Transporter Availability by Serotonin Transporter Promoter Gene Polymorphism." Biological Psychiatry 50 (1): 8-12.

Williams, R.B., D.A. Marchuk, K. M. Gadde, J.C. Barefoot, K. Grichnik, M.J. Helms, C.M. Kuhn et al. 2003. "Serotonin-related Gene Polymorphisms and Central Nervous System Serotonin Function." Neuropsychopharmacology 28 (3): 533-41.

Wojczynski, Mary K., and Hemant K. Tiwari. 2008. "Definition of Phenotype." Advances in Genetics 60: 75-105.

$\mathrm{Xu}, \mathrm{H}$., and S. Shete. 2007. "Mixed-effects Logistic Approach for Association following Linkage Scan for Complex Disorders." Annals of Human Genetics 71 (2): 230-37.

Young, Susan E., Andrew Smolen, John K. Hewitt, Brett C. Haberstick, Michael C. Stallings, Robin P. Corley, and Thomas J. Crowley. 2006. "Interaction between MAO-A Genotype and Maltreatment in the Risk for Conduct Disorder: Failure to Confirm in Adolescent Patients." American Journal of Psychiatry 163 (6): 101925

Zhu, Qin-shi, and Jean Chen Shih. 1997. “An Extensive Repeat Structure Down-regulates Human Monoamine Oxidase A Promoter Activity Independent of an Initiator-Like Sequence." Journal of Neurochemistry 69 (4): 1368-73.

Zuo, Yantao, David G. Gilbert, Norka E. Rabinovich, Hege Riise, Rachel Needham, and Jodi I. Huggenvik. 2009. "DRD2-related TaqIA Polymorphism Modulates Motivation to Smoke." Nicotine and Tobacco Research 11 (11): 1321-29. 